\title{
LOS INDEFINIDOS EN LA BIBLIA LATINA
}

The Latin Bible is the Latin document which uses the greatest number of indefinite pronouns. Some adjectives and nouns used as indefinites (homo, uir, anima, sermo, uerbum, proximus, amicus, frater, collega, uicinus, unus, omnis, uniuersus, cunctus) should be added to the standard list of classical and postclassical Latin indefinites, as also the participle in its paronomastic usage. These new indefinite pronouns in biblical Latin have their origins in the Hebrew from which the Latin translations of the Bible were made.

El uso de los indefinidos en el latín bíblico presenta, con respecto al uso clásico, cristiano o tardío, una serie de novedades, que han pasado desapercibidas a los autores de las sintaxis latinas, aun las más completas, pues ni siquiera dedican al tema una breve alusión. Y sin embargo, es un tema que vale la pena estudiar en profundidad, ya que la Biblia latina es el documento de toda la latinidad que más variedad de indefinidos emplea.

Comenzando por los datos más generales, diremos que el latín bíblico conoce y utiliza sin especiales novedades los siguientes indefi . nidos propiamente dichos del latín clásico ${ }^{1}$ : quis, "alguien» y en frases negativas "nadie»; aliquis, "alguien, alguno, algo»; quidam, "cierto"; quispiam, "alguien, alguno, algo»; quisquam, «alguien, alguno, algo", y en frases negativas, "nadie, nada, ninguno»; ullus, "alguien, alguno", $\mathrm{y}$ en frases negativas, "nadie, nada»; nonnullus, "alguien, alguno". Y los indefinidos negativos nemo, "nadie»; nihil, "nadax; nullus, "ninguno». Sólo faltan en las listas anteriores nonnihil, "algo»; nequis (preclásico) y neuter, "ninguno de los dos».

1 No daremos textos de los indefinidos que vamos a enumerar a continuación, pues cualquiera puede encontrarlos en las Concordancias Bíblicas habituales, como la Concordancia de Dutripon, o en la más reciente y exhaustiva de B. Fischer, Novae Concordantiae bibliorum sacrorum iuxta Vulgatam versionem critice editam,
5 vols., Stuttgart 1977 . 
Conoce y utiliza también, y con el mismo valor, los siguientes in definidos de distribución del latín clásico: quisque, "cada, cada uno"; unusquisque, "cada uno" y uterque, "cada uno de los dos". Conoce y utiliza asimismo los siguientes indefinidos de generalización del latín clásico: quisquis, "cualquiera, quienquiera"; quicumque, "cualquiera, quienquiera"; quiuis y quilibet, "cualquiera, quienquiera». Sólo faltan uteruis y uterlibet. Conoce y utiliza igualmente los siguientes indefinidos pronominales del latín clásico: alius, "otro" (entre varios) y alter, "otro" (entre dos); totus, "todo, entero", y unus, "uno". Las novedades en el uso de estos últimos indefinidos son las conocidas, debidas a la confusión entre alius y alter, y a la abundancia de unus como indefinido, que prepara el camino hacia unus como artículo indefinido. Como es sabido, los primeros indicios de este uso se remontan a la Vetus Latina y hay ejemplos en la Vulgata. Conoce y utiliza finalmente ciertos adjetivos con valor indefinido, como talis, "tal"; tantus, "tanto, tan"; quantus, "cuanto, cuan"; quot, "cuántos", etc.

En el uso de todos estos indefinidos el latín bíblico no ofrece especiales novedades, fuera de las consabidas y normales confusiones entre indefinidos de sentido muy afín, las cuales también existen en los autores profanos o cristianos de la época postclásica y tardía.

Pero a las listas anteriores hay que añadir, y ya como novedad absoluta, el uso en función de indefinidos de determinados sustantivos y adjetivos, tales como homo, uir, anima, sermo, uerbum, proximus, amicus, frater, collega, uicinus, mulier, socius, dux, unus, omnis, uniuersus, cunctus, además del participio usado paronomásticamente.

Para decirlo ya desde el principio, el origen del uso indefinido de los mencionados términos hay que buscarlo en último análisis en la lengua hebrea, de la que depende en este campo el latín bíblico, ya directamente en la Vulgata, ya indirectamente, a través del griego, en la Vetus Latina. Efectivamente, el hebreo, como la mayoría de las lenguas semíticas, carece de pronombres indefinidos, $y$, para llenar esta laguna, recurre a determinados sustantivos y adjetivos, que cumplen la función de indefinidos, como también la desempeña a veces el participio paronomástico ${ }^{2}$. Los sustantivos y adjetivos son los siguientes: 'adam = homo, uir; 'iš = homo, uir; nefes = anima; dabar $=$ uerbum, sermo; 'ah = frater; re' $a=$ proximus, amicus, collega, uicinus, socius; 'iššah = mulier; $k o l=$ omnis, uniuersus, cunctus, y 'ehad $=$ unus.

2 Cf. P. Joüon, Grammaire de l'hébreu biblique, Roma 19472, pp. 554 y 473; K. Beyer, Semitische Syntax im Neuen Testament, I 1, Göttingen 1968 2 , pp. 142 y 110. 
Pero veamos ahora cada uno de estos términos en su contexto bíblico inmediato para descubrir asi los distintos valores indefinidos que encierran.

\section{HOMO}

El sustantivo homo, como traducción del hebreo 'adam, «hombre», e 'iš, "hombre, varón", presenta en el latín bíblico varios empleos indefinidos, unos positivos y otros negativos, que podemos resumir en los siguientes apartados ${ }^{3}$ :

A) Usos positivos

1) Homo = "alguien, alguno": suple muchas veces a aliquis, quispiam, quisquam, ullus. He aquí algunos ejemplos:

Si dederit homo (alguien) omnem substantiam domus suae (Cant 8, 7).

$S i$ peccauerit homo (alguien) in proximum suum $(1 \operatorname{Re} 8,31)$. Obsérvese que en el texto paralelo de 2 Cro 6, 22 el traductor dice: Si peccauerit quispiam in proximum suum.

Quae faciens homo (alguien), uiuet in eis (Ez 20, 11, 13, 21; cf. Lev 18, 5; lo mismo en la Vetus Latina).

Plaga leprae si fuerit in homine (alguien) (Lev 13, 9; lo mismo en la V. L.). Homo (alguno) de filiis Israel... si quis (Lev 20, 2).

Homo si (si alguien, alguno) dormiens cum muliere (Lev 19, 20).

Homo si (si alguien, alguno) uouerit domum suam (Lev 27, 14).

2) Horno qui = "quien, el que, quienquiera que»: en esta fórmula, el término homo es pleonástico, pues no añade nada al sentido indefinido de qui en frases evidentemente condicionales. He aquí algunos ejemplos: Homo... qui (quien, el que, quienquiera que $=$ si alguno) fuerit leprosus (Lev 22, 4); Homo qui (quienquiera que $=$ si alguno) obtulerit uictimam (Lev 22, 21); Homo qui (quienquiera que = si alguno) obtulerit oblationem (Lev 22, 18); Homo qui obtulerit ex uobis hostiam (quienquiera de vosotros que $=\mathrm{si}$ alguno de vosotros) (Lev 1, 2: lo mismo en la $V . L$.); véanse otros textos en: Lev 27, 2; Num 9 , 10, etc. En otros pasajes de igual construcción Jerónimo traduce el término hebreo por qui, omitiendo el homo; por ej.: qui tetigerit inmundum (Lev 22, 4); qui tangit reptile (Lev 22, 5); qui comederit de sanctificatis (Lev 22, 14); cf. Lev 20, 9, 11, 13, 14, 15, 17, 20, 21, etc.

3 Algunos datos sobre el tema pueden verse en U. Rapallo, "Per una definizione diacronica e tipologica dei calchi ebraici nelle antiche versioni del Leviticon, RIL 103,1969 , p. 386 ss. 
Este segundo modelo de traducción justifica lo que decíamos acerca del valor pleonástico de homo.

3) Homo = «uno, cierto», y quizá "uno» con valor aproximado al artículo indefinido. He aquí algunos ejemplos tomados del N. T.:

Assimilatum est regnum caelorum homini regi (a un rey) (Mt 18, 23); simile est regnum caelorum homini regi (a un rey) (Mt 18, 23); simile est regnum caelorum homini patrifamilias (a un propietario) (Mt 20, 1); homo erat paterfamilias (había un propietario) (Mt 21, 33); quid prodest homini si mundum uniuersum lucretur? (¿qué aprovecha a uno ganar todo el mundo?) (Mt 16, 26); aut quam dabit homo commutationem pro anima sua? (o ¿qué dará uno a cambio de su vida?) (Mt 16, 26); quod accipiens homo, seminauit in agro suo ([un grano], que uno toma y siembra en su campo) (Mt 13,31); ... thesauro... quem qui inuenit homo, abscondit (tesoro, que al encontrarlo uno [alguien], lo esconde) (Mt 13, 44); quae enim seminauerit homo, haec et metet (lo que uno sembrare, eso recogerá) (Gal 6, 8). Y muchos ejemplos más.

Esta acepción de homo se conserva en el español medieval «omne» / "ombre", sobre todo cuando la palabra se usa sin artículo. He aquí algunos ejemplos de entre los muchísimos que se podrían aducir:

Libro de Alexandre: "desque se buelve omne (= uno) con ellos una vez» (54a); «un día gana omne (= uno) precio que sienpre dura» (71c); «nunca escusa muerte omne (a uno) por covardía» (674b); «deque omne (= uno) bien sabe que ave de morir» (675a); «que quando omne (=uno) pierde pariente o aver" (2388b): "quando omne (= uno) se cuida más seguro estar» (2394c); cf. además: 2421b; 2464bc; 2465a; 2660d; 2671c; 1174d; 1304d; 1469b; 1469c; etc.

Poema de Fernán González: «Por do quier que omne (= uno) los pudies amansar (202d); «deve aver el omne (=uno) grand seso en lidiar» (340b); «si omne ( $=$ uno) el su tiempo en valde quier passar» (348a); «pierde omne (= uno) buen precio en poco de mijero» (560d); «daría el omne ( $=$ uno) vozes e non sería oído» $(749 \mathrm{~b})$; etc.

Biblia medieval romanceada E64: «Por esto dexará ombre (= homo: uno) padre e madre" (Mt 19,5); «no ensuzia al hombre (=hominem: a uno) lo que por la boca entra, mas lo que sale por la boca, esso ensuzia al ombre» (=hominem: a uno) (Mt 15, 11); «pues tod aquel que escucha mis palauras e las faze, semejará al ombre (=uiro: a un) sabio que cimentó su casa... (Mt 7, 24); «e tod ombre que oye estas mis palauras e no las faze, semeja al hombre (=uiro: a uno) non sabio que fizo su

4 Sobre el empleo de «ombre» y «ombre del mundo" como indefinidos en la versión b́́blica medieval romanceada E6, cf. T. Montgomery, El Evangelio de San Mateo según el manuscrito escurialense I-I-6 (Anejos del Bol. de la R. A. E., VII), Madrid 1962, pp. 126 y 160. 
casa sobre arena» (Mt 7, 26); «otras muchas cosas hý ha que fizo Ihesús, que si las escrivies ombre (= uno: quae si scribantur) cada una sobre sí (Jn 21, 25); «mas deve ombre (= uno) meter vino nuevo en odres nuevos" (Mc 2, 22); "atal es el regno de Dios cuemo si echare ombre (= uno: homo) la semient en tierra* (Mc 4, 26); etc., etc.

Este valor indefinido de "omne» / «ombre» en el español medieval es cosa sabida; su origen inmediato y también remoto es el latín bíblico.

4) Homo = "cada uno": equivale a unusquisque o quisque. Hay ejemplos suficientemente claros: Reuertetur homo (volverá cada uno) ad possessionem suam (Lev 25, 10). El texto continúa: et unusquisque redeat (y vuelva cada uno) ad familiam pristinam; la equivalencia entre homo y unusquisque es evidente; cf. además Deut 3, 20 (unusquisque). Otro ejemplo: ... ut manducaret homo (de tal modo que comiera cada uno) carnes filii sui (Bar 2, 3). La equivalencia entre homo y unusquisque se confirma además por otros pasajes en los que Jerónimo traduce el 'iš hebreo por unusquisque, sobre todo en las fórmulas de reciprocidad, de las cuales hablaremos más adelante 5 .

5) Homo homo qui = "cualquiera que, quienquiera que». Es una fórmula redundante, imitada literalmente del hebreo, en la que homo homo es pleonástico, y equivale a quisquis o quicumque. He aquí algunos textos: Homo homo de domo Israel qui posuerit (cualquiera de la casa de Israel que ponga) (Ez 14, 4). Homo homo de domo Israel... si alienatus fuerit a me (cualquiera de la casa de Israel... si se alejare de mí) (Ez 14, 7). Obsérvese que aquí mismo se emplea quicumque solo en sustitución de homo homo: et de proselytis quicumque aduena...

6) Homo homo quicumque = "cualquiera que, quienquiera que». La fórmula es sinónima de la anterior, y también aquí la repetición de homo homo es una imitación literal del hebreo y un pleonasmo: Homo homo quicumque moechatus fuerit (quienquiera que cometa adulterio) (Lev 20, 10: V. L.; la Vg. traduce: Si moechatus quis fuerit).

7) Omnis homo qui = "cualquiera que, quienquiera que» (todo hombre que). Se trata evidentemente de una fórmula pleonástica en la que bastaría decir omnis qui o bien homo qui (véase antes esta fórmula), o simplemente qui en frases claramente condicionales, tenien-

5 Cf. O. García de la Fuente, «Expresión de la reciprocidad en el latín bíblico», Analecta Malacitana 5, 1982, pp. 163-172. 
do entonces el qui el sentido indefinido de "alguien», "alguno». He aquí los textos:

Omnis homo qui comederit uuam acerbam (quienquiera que coma las uvas agraces) (Jer 31, 30).

Omnis homo qui accesserit (quienquiera que se acerque) (Lev 22, 3; la V. L. omnis homo quicumque).

Omnis homo qui rogaret (quienquiera que rogara) (Dan 6, 12).

En otros textos semejantes sólo aparece la fórmula omnis qui para traducir la misma expresión hebrea, cf. Lev 15, 20, etc.

8) Omnis homo quicumque = "cualquiera que, quienquiera que». Esta fórmula, usada sólo por la Vetus Latina, equivale a la anterior y tiene la misma explicación que aquélla:

Omnis homo quicumque accesserit (quienquiera que se acerque) (Lev 22, 3; véase antes la $V g$.).

Omnis homo quicumque uenerit ad nos (quienquiera que venga a nosotros) (1 Mc 2, 41).

9) Homo quicumque = "cualquiera, quienquiera». En esta fórmula, traducida literalmente del hebreo, el sustantivo homo es pleonástico, pues en otros pasajes el traductor latino sólo traduce quicumque:

Homo quicumque de filiis Israel (cualquiera de los hijos de Israel) (Lev $17,13)$.

Homo quicumque tale composuerit (cualquiera que prepare otro semejante) (Ex 30, 33).

Homo quicumque fecerit simile (cualquiera que haga otro semejante) (Ex 30, 38).

Otras veces Jerónimo omite el homo, por ejemplo: quicumque macula-

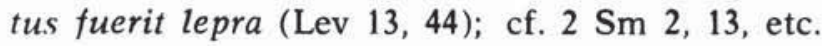

10) Homo quilibet $=$ "cualquiera, quienquiera". La fórmula traducida literalmente del hebreo supone el uso pleonástico de homo o de quilibet, ya que ninguna de las dos palabras añade nada a la otra. Jerónimo traduce la expresión hebrea de muchas maneras, como vamos viendo. He aquí los dos ejemplos de la Biblia:

Homo quilibet de domo Israel (cualquiera de la casa de Israel), si occiderit (Lev 17, 3).

Homo quilibet de domo Israel, et de aduenis (cualquiera de la casa de Israel y de los forasteros) (Lev 17, 10). 
11) Homo quisquam = "cualquiera, quienquiera", $y$, en frases negativas, "nadie, ninguno". También aquí hay un pleonasmo de homo, que nada añade al indefinido quisquam. Existe un solo texto en la Biblia con esta fórmula, y curiosamente no tiene correspondencia ni con el griego ni con el hebreo del Eclesiástico:

Ante mortem ne laudes hominem quemquam (antes de la muerte no alabes a nadie) (Ecclo 11, 30).

12) Homo quidam y quidam homo = "cierto hombre, un hombre, uno". Esta fórmula sólo aparece en el N. T. como traducción de óv $\theta p \omega-$

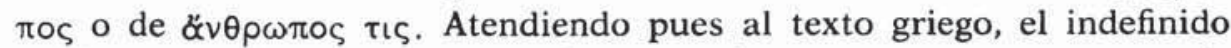
quidam es redundante y desde luego en algunos casos no corresponde al original. He aquí algunos textos de los muchos que podrían adu-

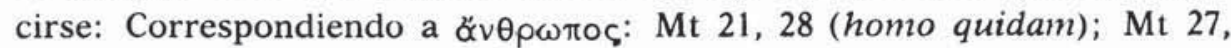

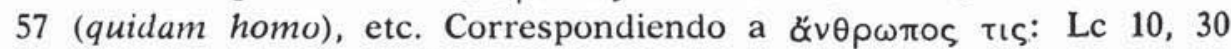
(homo quidam); Lc 12, 16 (homo quidam); Jud 4 (quidam homines), etc.

13) Quis hominum = "quien" o "alguien" en frases evidentemente condicionales; hominum es un pleonasmo que no añade nada al sentido indefinido de quis. Hay un ejemplo: Si quis hominum tetigerit lectum eius (si alguien [o quien] tocare su lecho) (Lev 15, 5).

\section{B) Usos Negativos}

En el latín bíblico, homo en combinación con una partícula de negación (non, nec, ne) o con un verbo negativo (nolo), precediendo o siguiendo al sustantivo, adquiere el significado nuevo de indefinido negativo ${ }^{6}$, equivaliendo entonces a nemo o nullus, "nadie o ninguno". Las combinaciones existentes en el latín bíblico son las siguientes:

1) Homo... non $=$ «nadie, ninguno»:

Homo non erat (no había nadie) qui operaretur terram (Gen 2, 5); homo de semine Aaron... non (nadie de la descendencia de Aarón) uescetur (Lev 22, 4); homo de semine tuo... qui habuerit maculam, non (nadie de tu descendencia... que tenga una mancha) offeret panes (Lev $21,17)$; hominem non contristauerit (no oprime a nadie) $(\mathrm{Ez} 18,7)$. $\mathrm{Y}$ otros textos semejantes. Jerónimo otras veces nos da la correspondencia latina exacta cuando traduce la expresión hebrea por nullus,

6 Cf. P. Joüon, o. c., p. 454; U. Rapallo, l. c., p. 398. 
por ejemplo: nullus (= lit. homo non) sit qui non ueniat $(2 \operatorname{Re} 10,19)$; nullus (= lit. homo non) ascendat tecum $(\operatorname{Ex} 34,3)$.

La expresión continúa en el griego del N. T., traducido luego al latín de esta manera: quod Deus coniunxit, homo non (= nadie) separet (Mt 19, 6; cf. Mc 10, 9); hominem non reuerebatur (no respetaba a nadie) (Lc 18, 2), etc.

El giro bíblico latino ha pasado al español medieval:

Libro de Alexandre: "nunca omne non vío niño tan acabado» (15b); "quando de muerte omne non puede estorcer» (72a); «omne a él llegarse sól non era osado» (109c); «desque omne de muerte non puede estorcer» (771a); «omne en tod el mundo contrastar no-l podrié (833d); «nunca omne non vío tan fiero a Bramante» (1352d); «que nunca omne bivo non las pudo saber" (2327b); "bien veyé que por omne nunca serié vengada" (2332a); "maguer omne non puede la cosa acabar» (167a); etc.

Poema de Fernán González: «nunca omne non vío dueña tan esforçada* (649b).

Berceo: San Millán: «en omne tal fereza que nunqua fue oída” (78d).

Sacrificio de la Misa: "nunca omne en sieglo non fizo tan mal seso" (209c).

Biblia medieval romanceada $E 6$ : «ni a ombre non he vergüença (= nec hominem reuereor) (ni respeto a nadie) (Lc 18,4$)$.

2) Non... homo / non... filius hominis = «nadie, ninguno»:

Las expresiones homo y filius hominis son sinónimas en el latín bíblico, y la segunda no es más que un hebraísmo para indicar «hombre».

a) Non... homo: «nadie, ninguno":

Non erat homo (no habia nadie) (Jer 4, 25); non habitat in eis homo (no habita nadie en ellas) (Jer 2, 6; cf. 4, 29); non accipiet homo (no tomará nadie) uxorem patris sui (Deut 22, 30); non cognouit homo (no conoció nadie) sepulcrum eius (Deut 34,6 ); non te uideat homo (que no te vea nadie) (Rut 3, 3); cf. Jer 32, 43; $1 \operatorname{Re} 8,36$; Is 38, 11; Dan 2, 10 , etc.

La expresión continúa en el N. T.: non iustificatur homo (no se justifica nadie) (Gal 2, 16), etc.

El giro latino ha pasado al español medieval. Los testimonios son numerosísimos:

Libro de Alexandre: "Que non es por nul vicio omne tan mal dañado" (2365c); «que non podiesse omne por nulla part foir» (2370b); «fuera tú non es omne que me pudiés vencer» (39b); «si prez non gana omne por dezir o por fer" (72c); "dixo: 'No-l prendrá omne, si yo non lo prisiero'» 
(115b); «que non puede vencer omne por muchedumne» (249b); «non te entienda omne que eres cavallero» (392b); «non los podrié en nada omne escatimar" (2395c); "non es omne nacido que-l pueda contrastar* (2431d); «no-l devisarié omne dó era ajuntado» (2542d); «a qual nunca llegó omne de madre nado" (2624d); "non serié omne bivo que non oviesse duelo" (2646b); "señor, non fue en omne nunca tal caridat" (2662c); cf. además: $832 \mathrm{~b}$; 943c; 999a; 1060d; 1064d; 1157d; 1175c; 1179b; 1194b; $1303 \mathrm{~b} ; 1506 \mathrm{~d} ; 1529 \mathrm{~d} ; 1661 \mathrm{c} ; 1688 \mathrm{c} ; 1721 \mathrm{~b} ; 1805 \mathrm{a} ; 2328 \mathrm{~d} ; 1819 \mathrm{c} ; 2125 \mathrm{~d} ; 2140 \mathrm{a}$; $2148 \mathrm{c} ; 2269 \mathrm{~b}$.

Poema de Fernán González: "Pero non puede omne la muerte esscusar» (209b); "verán un fuerte signo qual nunca vio omne nado» (239c); «tanto non fizo omne con tan poco poder» (262b); «non es omne en el mundo que podiesse endurar» (339a); "nunca más cosa viera omne nascido" (403d); cf. además: 535a; 552b; 605d; 621d.

Berceo: Sacrificio de la Misa: «no lo dio Dios a omne esto a entender* (121d).

Biblia medieval romanceada $E 6$ : "no tengo ombre (=hominem non habeo) que me meta en el albuhera» ( $\mathrm{Jn} 5,7)$; "non puede ombre recebir nada" (= non potest homo accipere quidquam) (Jn 3, 27); «un pollino... en que numqua cavalgó ombre» (Lc 19, 30); «assí que non podié ombre passar por aquella carrera (Mt 8, 28); "non digades a ombre del mundo (= nemini) esta visión» (Mt 17, 9); «no cataré a ombre (a nadie) d'aquí adelant" (non aspiciam hominem ultra) (Is 38, 11); "no a ombre (nadie) sobre la tierra" (non est homo super terram) (Dan 2, 10); "non vive ombre de pan solow (non in solo pane uiuit homo) (Mt 4, 4; cf. Lc 4, 4; Deut 8,3$)$. Esta frase nosotros hoy la conocemos bajo la forma, casi proverbial, de "no sólo de pan vive el hombre»; pero, en realidad, habría que traducirla por «nadie (=non homo) vive sólo de pan». Otros ejemplos: «non tome ombre (nadie) la muger de su padre (Deut 22, 30: versión medieval romanceada I-I-8; en adelante E8); «et no sopo ombre (nadie) su sepulcro» (Deut 34, 6: E8), etc. 7

b) Non... filius hominis: "nadie, ninguno»:

Non incolet eam filius hominis (que no la habite nadie) (Jer 49, 18); la misma frase en Jer 49, 33 y 50, 40; nec transeat per eam filius hominis (ni pase por ella nadie) (Jer 51, 43). El giro latino filius hominis aparece a veces en combinación con uir, y ambos son sinónimos; véase, por ejemplo, Jer 49, 18: non habitabit ibi uir, et non incolet eam filius hominis (no vivirá nadie allí, ni la ocupará nadie); lo mismo en Jer 49, 33. Pero aparece también, en frases negativas, en combinación con nullus, indicando así el verdadero significado de non filius hominis; Jer 51, 43: terra in qua nullus habitet nec transeat per eam filius hominis (tierra en la que nadie viva ni pase por ella nadie).

7 Cf. para otros ejemplos, T. Montgomery, o. c., pp. 126 y 160. 
La Biblia medieval romanceada E6 conserva en español estos giros latinos: "No morará hý varón e no labrará fi de ombre» (Jer 49, 18); "no fincará hý ombre ni la labrará fi de ombre" (Jer 49, 33); "no morará en ella ombre ni la labrará fi de ombre» (Jer 50, 40).

3) Omnis homo... non = "nadie, ninguno":

En esta fórmula el adjetivo omnis parece pleonástico, ya que nada añade al significado indefinido de homo. El significado de "nadie, ninguno" es evidente en los textos siguientes: Omnis homo... non accedet (ninguno [o nadie] se acercará) (Lev 18,6); omnes homines, qui uiderunt maiestatem meam... non uidebunt terram (ninguno de los que vieron mi majestad verá la tierra) (Num 14, 22).

El giro que comentamos se conserva en el español medieval. En el Libro de Alexandre encontramos frases como éstas: "non travarié a Ector tod ombre (= nadie) de la rienda" (704d); "tod ombre que-l vistiesse non (= nadie) serié tan cansado" (102c). Aquí, como se ve, aparecen las dos posibles combinaciones, es decir, con la negación delante del sustantivo: "non... tod ombre» (= non... omnis homo) o detrás: "tod ombre... non" (= omnis homo... non). La Biblia medieval romanceada E8 traduce así el texto de Num 14, 22: "mas todos los ombres que vieron la mi magestat... no verán la tierra»; se trata, pues, de una traducción totalmente literal, favorecida, sin duda, por la distancia que hay entre "todos los ombres» y el "no verán la tierra».

C) Usos Recfrrocos

Además de estos usos de homo hay que tener en cuenta su empleo como pronombre recíproco en las siguientes fórmulas bíblicas de reciprocidad:

a) Homo proximo suo (uno a otro) (Rut 4, 7);

b) Homo in proximum suum (uno contra otro) (1 Re 8, 31);

c) Homo contra proximum suum (uno en contra de otro) (Prov 25, 18);

d) Homo ad amicum suum (un [hombre] a otro) (Ex 33, 11).

En estas fórmulas derivadas directamente del hebreo, el término 'išs, "hombre», «alguien», "uno", unido a $r e$ ' $a$, "compañero, amigo, vecino, prójimo", sirve para indicar la reciprocidad ${ }^{8}$, y la fórmula bíblica equivale a la expresión clásica de la reciprocidad (desde Livio) alius alium o a la del latín tardío (desde Vitrubio), unus alterum.

8 Cf. P. Joüon, o. c., p. 454; O. García de la Fuente, l. c., p. 167 ss. 
II. VIR

El sustantivo uir, en cuanto traducción del hebreo 'iš, «hombre, varón», o 'adam, "hombre", presenta en el latín bíblico varios usos indefinidos, unos positivos y otros negativos, que podemos distribuir en los siguientes apartados:

A) Usos positivos

1) Vir = «alguien, alguno»; uiri = "algunos». La fórmula suple a quis, aliquis, quispiam, quisquam, ullus. He aquí algunos ejemplos:

Si occultabitur uir in absconditis? (¿se ocultará alguien en un escondite?) (Jer 23, 24).

Quomodo si fugiat uir (como si huyera alguien) a facie leonis (Am 5, 19). Surrexerunt ergo uiri (algunos) de senioribus terrae (Jer 26, 17).

Venerunt ad me uiri (algunos) de senioribus Israel $(\mathrm{Ez} 14,1)$. La misma frase en Ez 20, 1; etc.

2) Vir = "cada uno"; uiri = "cada uno de ellos». Equivale a unusquisque o quisque. He aquí algunos textos:

Reuertatur uir (vuelva cada uno) in domum suam $(1 \operatorname{Re} 12,24)$. En textos paralelos Jerónimo traduce unusquisque en lugar de uir: Reuertatur unusquisque in domum suam (1 Re 22, 17; véase la misma construcción en 2 Cro 11,$4 ; 18,16 ; 2 \operatorname{Sm~} 6,19$, etc.).

Conuertatur uir (conviértase cada uno) a uia sua mala (Jon 3,8 ). Véase la equivalencia con unusquisque: Reuertatur unusquisque a uia sua mala (Jer 18, 11).

Sedebit uir (se sentará cada uno) subtus uitem suam (Miq 4, 4). Véase la equivalencia con unusquisque: Sedit unusquisque sub uite sua (1 Mc 14, 14); habitabat unusquisque sub uite sua $(1 \operatorname{Re} 4,25)$.

Omnes reges... dormierunt in gloria, uir (cada uno) in domo sua (Is 14,18 ).

Timuerunt nautae, et clamauerunt uiri (cada uno de ellos) ad deum suum (Jon 1, 5) 9 .

9 Este significado de uir = "cada uno" puede pasar desapercibido si no se atien. de bien a texto y contexto; por ejemplo, la frase de Joel 2, 7: uir in uiis suis gra. dietur, desligada de todo contexto podría traducirse: "el hombre andará en sus caminos", y así es como la traduce el romanceador de la citada versión castellana medieval E6: "el hombre andará en sus carreras", sin darse cuenta de que uir no es «el hombre" sino "el saltamontes", y la frase quiere decir que "cada uno (de los saltamontes = uir) andará por sus caminos», sin torcerse ni a derecha ni a izquierda; cf. O. García de la Fuente, «Orden de palabras en hebreo, griego, latín y romanceamiento castellano medieval de Joel», EMERITA 51, 1983, pp. 41-61 y 185-213, en p. 210. 
3) Vir $=$ «uno, alguien». Equivale a quidam o a unus como indefinido:

Quasi uirum (a uno) qui suscitatur de somno suo (Zac 4, 1).

Sicut parcit uir (uno) filio suo (Mal 3, 17). Et uir si fuerit iustus (y si uno fuera justo) (Ez 18, 5). Y continúa en el N. T.: Ecce uir (uno) de turba exclamauit (Lc 9, 30); etc.

4) Vir quidam y quidam uir = "cierto hombre, un hombre, uno". Atendiendo al texto original, en esta fórmula quidam generalmente es redundante, es decir, basta el término uir para traducir el 'is hebreo. Así en los textos siguientes:

Fuit illo tempore uir quidam (un hombre, uno) de monte Ephraim (Jue 17, 1).

Fuit quidam vir (un) leuites (Jue 19, 1); cf. además $2 \mathrm{Sm} \mathrm{17,18;20,11,}$ 12 , etc. Pero otras veces quidam corresponde a 'ehad, «uno». Así en los pasajes siguientes: Erat autem quidam uir (un hombre) de Saraa (Jue 13, 2); tunc uir quidam (uno) de filiis prophetarum $(1 \operatorname{Re} 20,35$ ). Por último, Jerónimo a veces pone simplemente quidam para traducir el 'is hebreo; así en $1 \mathrm{Sm}$ 21, 7: erat autem ibi quidam (uno) de seruis Saul.

5) Unus uir quidam = "cierto hombre, un hombre». La fórmula sólo aparece una vez en la Vulgata como variante de un manuscrito; el texto ordinario omite el unus: unus uir quidam tetendit arcum (1 Re $22,34)$; en hebreo sólo hay 'iš, «(un) hombre».

6) Vir quispiam = «un hombre». El indefinido quispiam es añadido por Jerónimo; el hebreo sólo tiene 'is: erat autem uir quispiam in solitudine $(1 \mathrm{Sm} \mathrm{25,2).}$

7) Quis uirorum = "quien" o «alguien» en frases condicionales; uirorum es un pleonasmo que no añade nada al sentido indefinido de quis. En el apartado anterior vimos la expresión equivalente quis hominum. Hay un ejemplo: Si quis uirorum (si alguien [o quien]) uotum Domino uouerit (Num 30, 3).

\section{B) Usos negativos}

En el latín de la Biblia el sustantivo uir en combinación con una partícula de negación (non, nec, ne) o con un verbo negativo (nolo), precediendo o siguiendo al sustantivo, adquiere el significado nuevo 
de indefinido negativo, equivaliendo entonces a nemo, nullus, "nadie, ninguno». Las combinaciones son dos:

1) Vir... non $=$ "nadie, ninguno»:

Et uir non (nadie) eruet eam de manu mea (Os 2, 10).

Et uirum non contristauerit ( $\mathrm{y}$ a nadie causa mal) $(\mathrm{Ez} 18,16)$.

Et uir non (nadie) transibit per eam (Ez 44, 2).

Vir in iniquitate uitae suae non confortabitur (nadie por la maldad de su vida podrá resistir) (Ez 7, 13).

2) Non $\ldots$ uir $=$ "nadie, ninguno»:

Quia ueni et non erat uir (porque vine y no habia nadie) (Is 50, 2).

Et de gentibus non est uir mecum (y de entre las gentes no habia nadie conmigo) (Is 63, 3).

Per terram in qua non ambulauit uir (por la tierra en que no anduvo nadie) (Jer 2, 6). Cf. además: Is 59,16 ; Os 4, 4; Jer 29, 32; 33, 18; 9,$10 ; 49,18,33$; Sof 3,6 , etc.

El español medieval conserva los dos giros del latín bíblico. La versión española del siglo xIII conservada en el manuscrito escurialense I-I-6 (en adelante E6) traduce así algunas de las frases anteriores:

"e no fizier mal a ombre» ( $\mathrm{Ez} 18,16)$; «ni varón no passará por ella» (Ez 44, 2); "e de las yentes no a ombre conmigo" (Is 63, 3); "por tierra ó no andudo ombre» (Jer 2, 6); "no fincará hý ombre» = non manebit ibi uir (Jer 49, 33); "no morará hý varón" = non habitabit ibi uir (Jer 49, 18); "no morará en ella ombre» = non habitabit ibi uir $(\mathrm{Jer} 50,40) 10$.

\section{C) Usos RectProcos}

A estos usos de uir hay que añadir su empleo en el latín bíblico como pronombre recíproco en las fórmulas siguientes, que pueden agruparse en tres bloques. El primero está constituido por uir (en hebreo 'is o 'adam) en combinación con frater (en hebreo 'ah̆); el segundo, por uir en combinación con proximus, amicus, collega (en hebreo $r e^{\prime} a$ ); y el tercero, por uir en combinación con uir. Naturalmente, todas estas fórmulas están traducidas directamente del hebreo, en cuya lengua estos sustantivos en combinación sirven para expresar la reciprocidad ". He aquí las fórmulas:

10 Compárense estos textos con los que dábamos antes relativos a homo: hay textos en los que aparecen en combinación homo, uir y filius hominis.

11 Cf. P. Joüon, o. c., p. 454; O. García de la Fuente, «Expresión de la reciprocidad», l. c., p. 167 ss.

LII, $2 .^{\circ}-4$ 
1) Vir en combinación con frater:

a) Vir fratrem suum (uno a otro) (Is 3,6 ; Jer 9, 5; 19, 2; 13, 14; 23, 35; 25, 26; 31, 34; Miq 7, 2).

b) Vir fratri suo (non parcet) (nadie $[=u i r \ldots$ non $]$ perdona al otro) (Is 9, 19); uir fratri suo (uno a otro; unos a otros) (Zac 7,10$)$.

c) Vir (in gladio) fratris sui (uno [cada uno] por la espada del otro) (Ag 2, 23).

d) Vir a fratre suo (uno contra otro) (Jer 13, 14).

e) Vir contra fratrem suum (uno contra otro) (Is 19, 2).

2) Vir en combinación con proximus:

a) Vir proximum suum (uno a otro) (Jer 31, 34).

b) Vir proximo suo (uno a otro) (1 Mc 2, 40): es traducción de una fórmula griega, que continúa seguramente la fórmula hebrea 'iš... $r e^{*} a$.

c) Vir (manum) proximi sui (uno [la mano] del otro) (Zac 14, 13).

d) Inter uirum et proximum eius (entre uno y otro) (Jer 7, 5).

e) Vir ad proximum suum (uno a otro) (Jer 46, 16; Ez 33, 30).

f) Vir de proximo suo (uno de otro) (Ecclo 29, 23): este texto no tiene correspondencia griega ni hebrea.

3) Vir en combinación con amicus y collega:

a) Vir amicum suum (uno a otro) (Zac 3, 10).

b) Vir $a b$ amico suo (uno [= cada uno pida] a otro) (Ex 11, 2).

c) Vir contra amicum suum (uno [= cada cual] contra el otro) (Is 19, 2).

d) Vir ad collegam suum ([se dijeron] unos a otros) (Jon 1, 7).

4) Vir en combinación con uir:

Et iudicium fecerit inter uirum et uirum (e hiciere juicio [justo] entre uno[s] y otro[s]) (Ez 18, 8); et calumniabantur uirum, et domum eius; uirum, et haereditatem eius (y calumniaban a uno[s] y a su casa, a otro[s] y a su heredad) (Miq 2, 2); et reducam eos, uirum ad haereditatem suam, et uirum in terram suam (y los haré volver, cada uno a su heredad, y a cada cual a su tierra) (Jer 12, 15); et irruet, populus, uir ad uirum (y se lanzará la gente, unos contra otros) (Is 3, 5).

\section{ANIMA}

El sustantivo anima, en cuanto traducción del hebreo nefeš "alma" o del griego $\psi u \times \eta \dot{n}$ "alma», presenta en el latín bíblico varios usos indefinidos, unos positivos y otros negativos, que podemos agrupar en los siguientes apartados ${ }^{12}$ :

12 Sobre el empleo de nefeš-wuxh-anima, cf. P. Joüon, o. c., p. 454; U. Rapallo, l. c., p. 389 ss.; J. H. Becker, Het begrip nefes in het Oude Testament, Amsterdam 


\section{A) Usos positivos}

1) Anima = "alguien, alguno». En estos casos anima equivale a quis, aliquis, quisquam, quispiam, ullus. He aquí algunos textos:

Quod si peccauerit anima (alguien, alguno) per ignorantiam (Lev 4, 27). Si peccauerit anima (alguien, alguno), et audierit uocem (Lev 5,1$)$.

Anima (alguien, alguno) si praeuaricans caeremonias (Lev 5, 15); cf. Lev 2,$1 ; 5,17 ; 7,20$, etc. Véanse algunos textos en los que Jerónimo traduce nefes por quis (quae): Lev 22, 11: quae tetigerit immunditiam; Lev 29, 30: quae operis quippiam fecerit; cf. Lev 22, 11, etc.

2) Anima una $=$ «alguien, alguno». Es la misma fórmula anterior reforzada con el indefinido unus: Quod si anima una (si alguien, alguno) nesciens peccauerit (Num 15, 27).

3) Anima quae = «cualquiera que, quienquiera que». Esta fórmula de contenido indefinido corresponde literalmente al hebreo nefeš 'ašer:

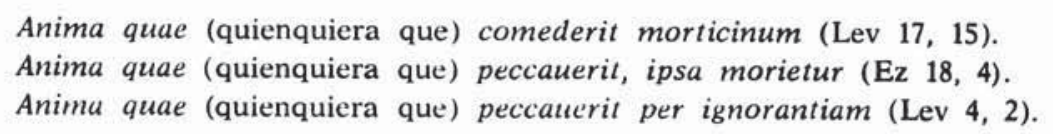

Véanse además los textos siguientes: Ez 18, 20; Lev 5, 2, 4; 6, 2; 20, 6; Num 13,$30 ; 19,22$, etc.

4) Omnis anima quae = "cualquiera que, quienquiera que». En esta fórmula el adjetivo omnis, como traducción del hebreo kol, «todo», es pleonástico, no aportando nada al significado indefinido de anima:

Omnis anima quae (quienquiera que) ederit sanguinem (Lev 7, 27).

Omnis anima quae (quienquiera que) fecerit de abominationibus his (Lev 18, 29); cf. Lev 23, 29 y en el N. T. Act 3, 23.

5) Quaecumque anima = "cualquiera que, quienquiera que». La fórmula es idéntica por el significado a anima quae. Hay un texto solo: Quaecumque anima (quienquiera que) tali se edulio contaminauerit (Lev 7, 18).

6) Omnis anima quaecumque = "cualquiera que, quienquiera que». Esta fórmula sólo aparece una vez en el N. T. como variante de omnis

1942, pp. 58-76 y 110-112; O. García de la Fuente, «Anima en la Biblia latina», Helmantica 29, 1978, pp. 14-15. 
anima quae: Omnis anima quaecumque (quienquiera que) non audierit prophetam (Act 3, 23: FSo).

7) Omnis anima $=$ "todos». La formula omnis anima equivale muchas veces a "todos" con sentido indeterminado; por ejemplo:

Fiebat autem omni animae timor (el temor se apoderaba de todos) (Act 2, 43); angustia in omnem animam hominis (angustia para todo hombre) (Rom 2, 9); omnis anima potestatibus... subdita sit (sométanse todos a las autoridades) (Rom 13, 1).

\section{B) Usos NEgativos}

En el latín bíblico el sustantivo anima en combinación con una partícula negativa (non), precediendo o siguiendo al sustantivo, adquiere el significado nuevo de indefinido negativo, equivaliendo a nemo o nullus, "nadie, ninguno» ${ }^{13}$. Las combinaciones son dos:

1) Omnis anima ... non = "nadie, ninguno»:

Omnis anima ex uobis non (nadie de vosotros) comedet sanguinem (Lev 17, 12).

2) Non ... omnis anima $=$ «nadie, ninguno»:

Non igitur ultra percutiam omnem animam uiuentem sicut feci (no volveré a castigar a ningún viviente como lo hice) (Gen 8, 21).

\section{VERBVM}

El sustantivo uerbum en cuanto traducción del hebreo dabar, "palabra" y "cosa», tiene a veces en el latín bíblico el valor de pronombre indefinido, positivo o negativo, como indican los apartados siguientes ${ }^{14}$ :

A) Usos positivos

1) Verbum = «algo». Equivale a aliquid o quidquam.

13 Cf. O. García de la Fuente, "Anima», l. c., p. 15.

14 Para estos significados, cf. P. Joüon, o. c., p. 454; O. García de la Fuente, «Sermo y uerbum en la Biblia latina*, Actas del $V$ Congreso Esp. de Est. Cl., Madrid 1978, pp. 725-732. 
Numquid impossibile est a Deo uerbum? (¿hay algo imposible para Dios? (Gen 18, 14: V. L.). La Vulgata usa la construcción clásica normal: Numquid Deo quidquam est difficile?

2) Omne uerbum = "algo». El adjetivo omnis en este caso sería pleonástico, pues no añade nada al sentido indefinido de uerbum:

Numquid mihi difficile erit omne uerbum? (¿habrá acaso algo difícil para mí?) (Jer 32, 27). Cabe también otra interpretación, es decir, dar a uerbum el significado de "cosa", como efectivamente lo tiene muchas veces (cf. Gen 18, 25; 19, 21; 22, 16; 24, 9; 30, 31; 34, 14, 19; 37, 11; 41, 28; 44,$7 ; 45,27$ : todos en la $V$. $L$., etc.), y el adjetivo omnis tendría el valor del indefinido aliquid: ¿habrá acaso alguna cosa difícil para mí?

\section{B) Usos negativos}

En el latín bíblico uerbum en combinación con una partícula de negación (non, nec, ne) o un verbo negativo (nolo), precediendo al sustantivo, adquiere el significado nuevo de indefinido negativo, equivaliendo a nihil, "nada». He aquí las varias combinaciones ${ }^{15}$ :

1) Non... uerbum = "nada $:$

Numquid non est uerbum? (¿acaso no hay nada?) (1 Sm 17, 29).

Et non respondit ei populus uerbum (y el pueblo no le respondió nada) $(1 \operatorname{Re} 18,21)$. Ne abscondas a me uerbum, quod te interrogo (no me escondas nada de lo que te pregunto) (2 Sm 14, 18). Quia non facit Dominus uerbum (porque el Señor no hace nada) (Am 3, 7). Nolite facere uerbum abominationis (no hagáis nada abominable) (Jer 44, 4). Non fuit uerbum (no hubo nada) quod non ostenderet eis Ezechias (Is 39,2$)$. La expresión continúa en el N. T.: Non respondit eis uerbum (no les respondió nada) (Mt 15, 23).

Esta expresión latina continúa en los giros españoles «ni palabra» o "ini palabra!», equivalentes a "no saber nada», "no enterarse de nada"; "no saber palabra"; "no saber ni una palabra"; "no decir palabra»; "no decir ni palabra»; "no hablar palabra»; "no hablar ni palabra»; "no soltar palabra»; "no dejar escapar palabra»; «sin decir palabran.

2) Non... omne uerbum $=$ «nada .

El adjetivo omnis es pleonástico, no añadiendo nada al sentido indefinido de uerbum:

15 Cf. O. García de la Fuente, «Sermo», l. c., p. 729. 
Non erit impossibile apud Deum omne uerbum (no hay nada imposible para Dios) (Lc 1, 37). Aunque el texto aparece en el N. T., es una continuación de la expresión hebrea non... omnis, que estudiaremos más adelante.

Non erit tibi difficile omne uerbum (no hay nada difícil para ti) (Jer $32,17)$.

3) Non... ad ullum uerbum = «a nadaw:

Et non respondit ei ad ullum uerbum (y no le respondió a nada) (Mt 27, 14).

\section{SERMO}

El sustantivo sermo en cuanto traducción del hebreo dabar, "palabra» $\mathrm{y}$ "cosa", tiene a veces en el latín bíblico la acepción nueva de pronombre indefinido, positivo o negativo, como indican los apartados siguientes ${ }^{16}$ :

A) Usos positrvos

1) Sermo $=$ «algo». Corresponde a aliquid.

Quis est sermo, quem locutus est Dominus ad te? (¿qué es lo que [la cosa que] te ha dicho el Señor?)... haec faciat tibi Deus... si absconderis a me sermonem ex omnibus uerbis, quae dicta sunt tibi (que Dios te haga esto... si me ocultas algo de todas las cosas que se te han dicho) (1 Sm 3, 17).

Rex praecepit mihi sermonem, et dixit: Nemo sciat rem (el rey me ha ordenado algo [una cosa], diciendo que nadie sepa el asunto) (1 $\mathrm{Sm}$ 21, 2).

Et dixit: Putasne est sermo a Domino? (y dijo: chay algo de parte del Señor?) (Jer 37, 16).

Interrogo ego te sermonem; ne abscondas a me aliquid (voy a preguntarte yo algo [una cosa]; no me ocultes nada) (Jer 38, 14).

La expresión continúa en el N. T.: Interrogabo uos et ego unum sermonem, quem si dixeritis mihi... (voy a preguntaros yo también algo [una cosa], y si me lo decís...) (Mt 21, 24).

16 Para toda esta cuestión, cf. O. García de la Fuente, «Sermo», l. c., p. 731. 


\section{B) Usos Negativos}

En latín bíblico sermo en combinación con una partícula negativa, generalmente non, precediendo al sustantivo, adquiere el significado nuevo de indefinido negativo, equivaliendo a nihil, "nada» ${ }^{17}$.

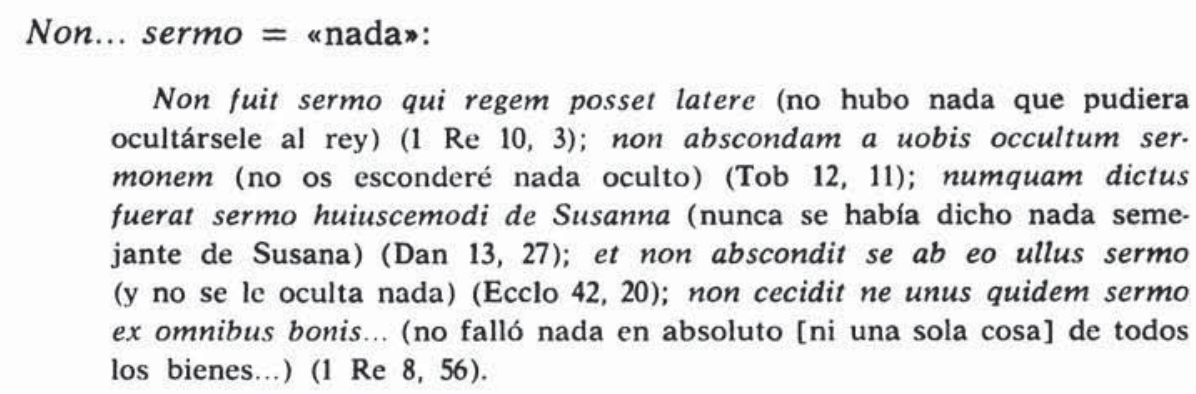

\section{OMNIS}

El adjetivo omnis en cuanto traducción del hebreo $k o l$, "totalidad, todo", tiene a veces en el latín bíblico la acepción nueva de pronombre indefinido, positivo o negativo, como puede constatarse por las explicaciones siguientes:

\section{A) Usos positivos}

1) Omnis = "cualquiera, quienquiera»: suple a quisquis o quicumque 18; he aquí algunos textos: loquere ad Aaron... ne omni tempore ingrediatur sanctuarium (habla a Aarón [y dile] que no entre en el santuario en cualquier tiempo) (Lev 16, 2). Aarón podía entrar en el santuario, pero no en cualquier momento, sino en el tiempo establecido. Non omnem hominem inducas in domum tuam (no metas en tu casa a cualquier hombre) (Ecclo 11, 31); non omni homini cor tuum manifestes (no descubras tu corazón a cualquier hombre) (Ecclo 8, 22); non uentiles te in omnem uentum, et non eas in omni uia (no avientes a cualquier viento, y no vayas por cualquier camino) (Ecclo 5, 11); imprecatio, quae acciderit omni homini de populo tuo ([la señal de] la maldición que viniera sobre cualquier hombre de tu pueblo) (1 $\mathrm{Re}$ 8, 38); omnis qui occiderit Cain (quienquiera que matara a Caín) (Gen

17 Cf. O. García de la Fuente, "Sermo», l. c., p. 731.

18 Para este significado de $k o l=$ omnis, cf. P. Joüon, o. c., p. 432. 
4, 15); quid est omnis caro (qué es cualquier hombre) ut audiat uocem Dei? (Deut 5, 26); omnis qui tetigerit montem (quienquiera que toque el monte), morte morietur (Ex 19, 12), etc.

2) Omnis = "cada uno": equivale a unusquisque; he aquí algunos textos: quia omnis (= cada uno) hypocrita est et nequam (Is 9, 17); quia a minimo usque ad maximum, omnes (= cada uno de ellos) auaritiam sequuntur (Jer 8, 10); cf. además: Is 1, 23; 15, 3; Jer 20, 7; Hab 1, 9; etc. ${ }^{19}$

3) Omne = «algo, alguna cosa». El texto de Jer 32, 27: numquid mihi difficile erit omne uerbum? (¿habrá acaso algo [o alguna cosa] difícil para mí?) admite esta interpretación, como dijimos antes.

\section{B) Usos negativos}

En el latín bíblico el adjetivo omnis en combinación con una partícula negativa (non, nec, ne) o un verbo de negación (nolo), precediendo o siguiendo al adjetivo, adquiere el significado nuevo de indefinido negativo, equivaliendo entonces a nihil, nemo, nullus, "nada, nadie, ninguno». Se trata de la traducción literal del giro hebreo lo' kol, "no todo", o 'al kol, "no todo", con el cual la lengua hebrea suple la carencia de los indefinidos "nada, nadie, ninguno" ${ }^{20}$. La negación en hebreo puede ir delante o detrás de $\mathrm{kol}$, de ahí las dos posibilidades que ofrece el latín bíblico.

1) Omnis... non = "nada, nadie, ninguno"; he aquí algunos ejemplos: Omne fermentatum non comedetis (no comeréis nada fermentado) (Ex 12, 20); Omne sanctum non tanget (no tocará nada santo) (Ex 12, 4); omnis macula non erit (no habrá ninguna mancha) (Lev 22, 21); omne opus seruile non facietis in eo (no haréis en él ningún trabajo servil) (Lev 23, 7). Y muchísimos otros textos, tanto del Antiguo como del Nuevo Testamento ${ }^{21}$.

19 Cf. P. Joüion, o. c., p. 453.

20 Para este tema, cf. P. Joüon, o. c., p. 492 s.; U. Rapallo, l. c., p. 398 ss.; K. Beyer, o. c., pp. 189 y 213; O. García de la Fuente, «Uso de non omnis y omnis non por nihil, nemo, nullus en los salterios latinos», Helmantica 27, 1976, pp. $261-271$.

21 He aquí algunos textos: Ex 12, 43; Lev 7,$26 ; 10,9 ; 11,44 ; 17,12 ; 18,6$; 18,$23 ; 18,24 ; 21,11 ; 22,10,13 ; 23,3,21,25,28,29,35,36 ;$ Num $6,5,6 ; 28,18$, 25; 29, 1, 7, 35; 1 Sm 1, 15; Job 1, 22; 2, 10; Prov 2, 19; 3, 15; 8, 11; Eccle 2, 10; Is 33,$20 ; 54,17 ; 56,6 ; 63,9 ;$ Jer 2,$24 ; 3,10 ; 9,4 ; 17,22 ; 32,23 ;$ Ez 9,$6 ; 18,22$; 18,$24 ; 28,3 ; 31,8 ; 33,16$; Dan $4,6,15 ; 6,4,15 ; 8,4 ;$ Os 12,8 ; Hab 2 , 19; y continúa en textos redactados en griego y en el N. T.: 1 Mc 2, 61; Ecclo 18, 15; 21, 17; 
Este giro se conserva en el español medieval. En el Libro de Alexandre se encuentran versos como éstos: "En todas sus comarcas non nacen nunca flores» (2344a); "por todos los peligros non fue quebrantado» (2432c, ms. P; el ms. O tiene "nunca» en vez de «non»); «tod omne que-l vistiesse non serié tan cansado» (102c). Y la Biblia medieval romanceada E6 traduce así algunos de los giros bíblicos que estudiamos: "todo vaso... non será endereçado contra ti" (=omne uas... contra te non dirigetur) (Is 54, 17), cuyo sentido es: "ningún vaso se dirigirá contra ti»; "toda casa repartida entre sí non durará" (omnis... domus diuisa contra se non stabit) (Mt 12, 25); "toda cosa que entre en el ombre no-l puede ensuziar" (omne extrinsecus introiens in hominem non potest eum communicare) (Mc 7, 18); «porque tod ombre que cree en él non perezca” (ut omnis qui credit in eum non pereat) (Jn 3,16$)$; etcétera.

Esta versión, no obstante, conoce perfectamente el giro que hoy empleamos, y lo utiliza muchas veces; por ejemplo: «assí ningún de vos, que no niega todo quanto ha, non puede seer mío diciplo» (sic omnis ex uobis, qui non renuntiat omnibus quae possidet, non potest meus esse discipulus) ( $\operatorname{Lc} 14,33)$; «e ninguna bestia no le podié defender» (et omnes bestiae non poterant resistere ei) (Dan 8,4$)$; «e no a en ellos ningún espírito" (et omnis spiritus non est in uisceribus eius) (Hab 2, 19), etc.

2) Non ... omnis = "nadie, nada, ninguno»:

Non facies omne opus (no harás ningún trabajo) (Ex 20, 10); cum interierit non sumet omnia (cuando muera no se llevará nada) (Sal 48, 18); et uinum non bibet omnis sacerdos ( $\mathrm{y}$ no beberá vino ningún sacerdote) (Ez 44, 21). Y otros muchísimos textos, tanto del Antiguo como del Nuevo Testamento 22.

Este giro se conserva igualmente en el español medieval. En el Libro de Alexandre leemos frases como éstas: "Non travarié a Ector tod omne de la rienda" (704d). En la Biblia medieval romanceada E6 es normal encontrar traducciones como éstas: "Non quieras mentir

23,$20 ; 26,20 ; 31,27 ; 42,12 ;$ Mt 12,$25 ;$ Mc 7,18 ; Lc 14,$33 ;$ Jn 3,$16 ; 11,26 ; 12$, 46 , etc., etc.

22 He aquí algunos textos: Gen 4,$15 ; 8,21 ; 9,11 ; 14,23 ; 19,17 ; 20,17$; Ex 35 , 3; Lev 18, 26; Deut 5, 8; 12, 13, 19; 16, 21; 22, 19; $1 \mathrm{Sm} \mathrm{3,19;1} \mathrm{Re} \mathrm{15,} \mathrm{5;} 2 \operatorname{Re} 13$, $11 ; 14,24 ; 22,20$; Job 13,$16 ; 33,13$; Sal 13,$4 ; 33,11,23 ; 52,5 ; 58,6 ; 77,38 ; 102,2$; 113,$25 ; 118,133 ; 142,2 ; 147,20$; Is 56,2 ; Jer 17,$24 ; 32,17 ; 43,3$; Lam 2 , 2; Ez 4 , $14 ; 12,24 ; 12,28 ; 14,23 ; 31,14 ; 44,13$; Dan 3,95 ; Os 7,10 ; Hab 2,6 ; y continúa en los textos redactados en griego y en el $\mathrm{N}$. T.: Ecclo 7,$14 ; 22,20 ; 22,23$; 33,$21 ; 33,30 ; 37,14 ; 37,32$ (dos veces); 42,$20 ;$ Mt 24, 22; Lc 1, 37, etc. 
toda mentira (noli uelle mentiri omne mendacium) (Ecclo 7, 14), cuyo sentido es: "no quieras decir ninguna mentira»; «non será justa toda carne" (non iustificabitur omnis caro) (Gal 2, 16), cuya traducción correcta sería: "nadie será justificado»; "e no fizier todas estas cosas» (et haec omnia non facientem) $(\mathrm{Ez} 18,11)$, cuya traducción sería: "y si no hace ninguna de estas cosas»; "e non serán rotas todas las sus cuerdas” (et omnes funiculi eius non rumpentur) (Is 33, 20), cuyo sentido es: "y no será rota ninguna de sus cuerdas»; "no falleçrán todos los que la demandan" (omnes qui quaerunt eam non deficient) (Jer 2, 24), cuya traducción correcta sería: "no fallará ninguno de los que la buscan», etc.

Pero esta antigua versión castellana conoce perfectamente el giro correcto que hoy empleamos, y lo utiliza también abundantemente; véanse los ejemplos siguientes: "Non fagades obra ninguna" (ne faciatis in eo omne opus) (Jer 17, 24); "e non bevrá vino ningún sacerdot" (et uinum non bibet omnis sacerdos) ( $\mathrm{Ez} 44,21)$; "no escaparié ninguna carne» (non fieret salua omnis caro) (Mt 24, 22); "e no entró en $\mathrm{mi}$ boca ninguna carne no limpia» (et non est ingressa in os meum omnis caro inmunda) (Ez 4, 14); "non passa d'él ningún pensamiento" (non praeterit illum omnis cogitatus) (Ecclo 42, 20); en este mismo verso aparece la otra construcción latina clásica, es decir, non... ullus en vez de non... omnis, y nuestro autor la traduce correctamente por: "non se asconde d'él ninguna palabra" (non abscondit se ab eo ullus sermo); "mientre vives e as espírito non te camie ninguna carne" (dum adhuc superes et aspiras non immutabit te omnis caro) (Ecclo 33, 21); "non seas gargantoso en ningún comer, e non te viertas sobre ninguna vianda” (noli auidus esse in omni epulatione, et non te effundas super omnem escam) (Ecclo 37, 32), y otros muchos ejemplos más.

En el español del siglo xIII era normal decir "sin todo" como equivalente de "sin ninguno", pues así lo demuestran los ejemplos siguientes: "E tú paristi, Virgo, sin toda lesión" (Berceo, Loores, 7d); "en paz que la contenga e sin toda contienda" (Berceo, Sacrif. de la Misa, 102b); "dolava en los griegos sin toda piadat" (Alexandre, 1017d); "y estos paños serán limpios e sin todo sudor" (Biblia romanceada E6: Ez 44, 18). La expresión española es la continuadora de la latina bíblica non... omnis.

\section{VNIVERSVS}

El adjetivo uniuersus en cuanto traducción del hebreo kol, "todo", tiene a veces en el latín bíblico el significado nuevo de pronombre 
indefinido negativo, "nadie, ninguno", cuando va combinado con una partícula negativa (non, nec, ne), que precede o sigue al adjetivo. Se trata de la traducción literal del mismo giro hebreo que comentábamos a propósito de omnis. Las combinaciones son dos ${ }^{23}$ :

1) Vniuersus... non $=$ «nadie, ninguno»:

Sanguinem uniuersae carnis non comedetis (no comeréis la sangre de ninguna carne) (Lev 17, 14).

Vniuersi, qui sustinent te, non confundentur (ninguno de los que esperan en ti serán confundidos) (Sal 24,3 ).

2) Non... uniuersus $=$ "nadie, ninguno»:

Non manducauit uniuersus populus panem (nadie del pueblo probó bocado) $(1 \mathrm{Sm} \mathrm{14}, 24)$.

Non est pax uniuersae carni (no hay paz para nadie) (Jer 12, 12).

Non elegi ciuitatem de uniuersis tribubus Israel (no elegí una ciudad de ninguna tribu de Israel) (1 $\operatorname{Re} 8,16)$. Otros ejemplos en Jos 11, 15; $1 \operatorname{Re} 10,22 ; \operatorname{Jer} 18,18$, etc.

\section{CVNCTVS}

El adjetivo cunctus en cuanto traducción del hebreo kol, "todo", tiene a veces en el latín bíblico el significado nuevo de pronombre indefinido negativo, "nadie, ninguno», cuando va unido a una partícula de negación (non, nec, ne), que precede o sigue al adjetivo. Se trata del mismo giro hebreo que comentábamos a propósito de omnis y uniuersus. Las combinaciones con cunctus son dos:

1) Cunctus... non $=$ «nadie, ninguno»:

Cunctis diebus terrae... nox et dies non requiescent (en ningún día [de existencia] de la tierra... cesarán la noche y el día) (Gen 8,22$)$.

2) Non... cunctus $=$ "nadie, ninguno":

Non elegi ciuitatem de cunctis tribubus Israel (no elegi una ciudad de ninguna tribu de Israel) ( 2 Cro 6,5 ; véase antes la misma frase con el adjetivo uniuersus).

Neque polluentur ultra in... cunctis iniquitatibus suis (ni se mancharán más con... ninguna de sus iniquidades) ( $\mathrm{Ez} 37,23)$.

Et ne excidant de corde tuo cunctis diebus uitae tuae (y no se aparten de tu corazón en ningún día de tu vida) (Deut 4,9 ). Otros textos en Ex 13 7; Num 6, 3, 4; Deut 6, 14; 22, 29; 23, 6; Jer 35, 8, etc.

23 Cf. O. García de la Fuente, «Uso de non omnis», l. c., p. 263 ss. 


\section{VNVS}

Sobre el empleo de unus en la Biblia latina hay que señalar varios usos del término, unos comunes con el latín clásico y tardío, y otros propios del latín bíblico. Estos usos dependen del significado de la palabra hebrea 'ehad, "uno» (f. 'ahat, "una»), que presenta un campo semántico muy amplio ${ }^{24}$, ya que, junto al significado básico de «uno» -numeral- y «uno solo, único», tiene también las acepciones de "primero", "cada uno", «otro", «el mismo», «uno cualquiera», «tal», "algo». Algunos de estos significados han pasado al latín bíblico en forma de calcos semánticos.

1) Entre los u sos comunes con el latín clásico y tardío baste señalar su empleo como adjetivo, "solo, único», como numeral, «uno», y como indefinido, "uno, cierto» - quidam-, subrayando únicamente que aumenta su empleo como tal indefinido en relación a la época clásica.

2) Entre los usos propios de la Biblia vamos a agrupar los textos en dos grandes bloques, uno referente al empleo de unus con valor positivo y otro con valor negativo.

\section{A) Usos positivos}

1) Vnus como numeral ordinal = "primero" 25: Hay textos en donde este significado es evidente, pues el traductor latino hace una enumeración, comenzando por unus y siguiendo por secundus, tertius, etc. Así en Gen 1, 4: dies unus (día primero); luego traduce, dies secundus (v. 8); dies tertius (v. 13), etc.; Lev 23, 24: una die mensis (V. L.) (día primero del mes) = prima die mensis $(V g.) ; 1 \mathrm{Sm} \mathrm{1,} \mathrm{2:} \mathrm{nomen} \mathrm{uni}$ (= primera) Anna, et nomen secundae Phenenna; $\mathrm{Ag} 1,1:$ in anno secundo, in mense sexto, in die una mensis (= el día primero del mes): en Gen 8, 5, 13, por ejemplo, el traductor dice: prima die mensis, al traducir la misma expresión hebrea. Otros textos: Esdr 1, 1; 10, 16; Dan 9, 2, etc. Este uso continúa en el griego del N. T. y pasa al latín: una sabbati (= el primer día de la semana) (Lc 24, 1; cf. Jn 20, 1, etc.).

24 U. Rapallo, 1. c., p. 412 ss.

25 P. Joüon, o. c., pp. 438 y 441; U. Rapallo, l. c., p. 415 s.; L. Köhler - W. Baumgartner, Hebräisches und aramäisches Lexikon zum Alten Testament, Leiden $1967_{3}$ p. 30 (s. v.). 
2) Vnus como demostrativo $=$ "el mismo": equivale a idem ${ }^{26}$ : Este significado de unus resulta evidente en algunos textos en donde concurre con par o idem, como, por ejemplo: 1 Re 6, 25: in mensura pari et opus unum (= el mismo) erat in duobus; Gen 11, 1: erat autem terra labii unius (= la misma lengua) et sermonum eorumdem ( $=$ las mismas palabras). Pero también es claro este significado en otros muchos textos; por ejemplo: 1 Re 3, 17: ego et mulier haec habitabamus in domo una (= en la misma casa); Gen 27, 45: cur utroque orbabor filio in uno die? (= en el mismo día); Mal 2, 10: numquid non pater unus (= el mismo padre) omnium nostrum?; numquid non Deus unus (= el mismo Dios) creauit nos?; Lev 22, 28: non immolabuntur una die (= el mismo día) cum foetibus suis; Gen 41,11 : ubi una nocte (= la misma noche) uterque uidimus somnium; $2 \mathrm{Sm} \mathrm{12,1:} \mathrm{duo} \mathrm{uiri} \mathrm{erant}$ in ciuitate una (= en la misma ciudad); etc. Este uso existe también en autores tardíos, a partir de Petronio ${ }^{27}$, pero no con la frecuencia con que aparece en el latín bíblico; además, en este tipo de latín depende del hebreo.

3) Vnus como pronombre indefinido:

a) Vnus = "uno cualquiera": equivale a quisquis o quicumque ${ }^{28}$ :

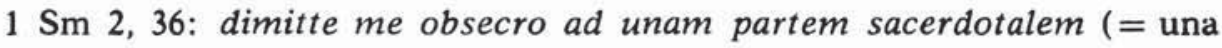
división sacerdotal cualquiera). Jerónimo en otros lugares traduce el 'ehad hebreo, no por unus sino por quicumque, por ejemplo: $2 \mathrm{Sm} \mathrm{17,}$ 12: et irruemus super eum in quocumque loco (lit. in uno loco) inuentus fuerit.

b) Vnus = "tal»: equivale a talis ${ }^{29}: 2 \mathrm{Sm} \mathrm{15,2:qui}$ respondens aiebat: Ex una tribu Israel ego sum (= yo soy de tal tribu de Israel).

c) Vnus = "cada uno": equivale a quisque o unusquisque ${ }^{30}: \mathrm{Ez} 1$, 6: quatuor facies uni (cada uno tenía cuatro caras), et quatuor pennae uni (y cada uno tenía cuatro alas).

d) Vnus = "algo, alguna cosa»: equivale a aliquid, quidquam ": Lev 6, 3: et de uno ab omnibus (= algo o alguna de todas estas cosas) fecerit $(V$. L.); la Vulgata da la equivalencia: quodlibet aliud ex pluri-

to Cf. P. Joüon, o. c., p. 454; L. Köhler - W. Baumgartner, o. c., p. 29.

27 Cf. Leumann-Hofmann-Szantyr, Lateinische Grammatik, II, Munich 1972, p. 188.

28 Cf. P. Joüon, o. c., p. 428; L. Köhler-W. Baumgartner, o. c., p. 29.

29 Cf. P. Joüon, o. c., p. 428.

30 Cf. L. Köhler-W. Baumgartner, o. c., p. 30.

31 Cf. U. Rapallo, l. c., p. 415. Para completar la materia puede recordarse aqui el uso del femenino una con valor del neutro sustantivado (unum): unam petii a Domino (= una cosa he pedido al Señor), hanc requiram (Sal 26,4 ). 
bus fecerit; Lev 6, 7: de uno ab omnibus (alguna de todas estas cosas) $(V . L)=$. pro singulis $(V g$.$) ; Lev 4,22$ : et fecerit unum e pluribus $(V . L$. y $V g$.) (alguna de estas cosas); Lev 4, 2: et de uniuersis unum fecerit $(V$. L.) (hiciera alguna de todas estas cosas): la Vulgata da la correspondencia: de uniuersis mandatis... quippiam fecerit; Lev 4, 27: ut faciat unum de his (V. L.) (= haga alguna de estas cosas): la Vulgata da la correspondencia: ut faciat quidquam de his. Advertimos, sin embargo, que todos estos textos admiten también la equivalencia entre unus y quisquis o quicumque; es decir, en vez de "algo» o «alguna cosa» pudiera interpretarse "cualquier cosa», "cualquiera de estas cosas».

4) Vnus en fórmulas de reciprocidad: La fórmula de reciprocidad unus unum aparece ya en Cicerón con un ejemplo, pero se usa sobre todo en el latín tardío ${ }^{32}$. En el latín bíblico esta expresión está representada por las variantes: una uni, unum contra unum y unus et unus: Job 41, 7: una uni coniungitur (están unidos uno a otro): en el verso siguiente, Jerónimo emplea otra fórmula de reciprocidad: una alteri adhaerebit (están pegados uno a otro). Is 27, 12: et uos congregabimini unus et unus, filii Israel (y seréis reunidos uno tras otro, hijos de Israel). Ecclo 33, 15: duo et duo, et unum contra unum (de dos en dos, una frente a otra); Ecclo 42, 25: omnia duplicia, unum contra unum (de dos en dos [= todas duplicadas], una frente a otra). En los dos primeros ejemplos se trata de traducciones literales del hebreo: 'ehad be-'ehad (Job 41, 7): le'ahad 'ehad (Is 27, 12) ${ }^{33}$; en los dos últimos se

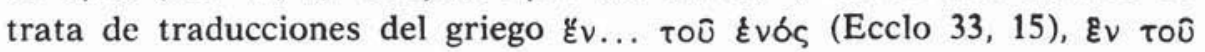
Évós (Ecclo 42, 25).

5) Vnus como artículo indeterminado: "uno» ${ }^{34}$ : El uso de unus en función de artículo indeterminado entra por primera vez en latín de manera inequívoca a través de la Vetus Latina, pero se encuentran también huellas evidentes en la Vulgata: he aquí algunos textos bastante claros de la Vulgata; y adviértase que en todos ellos el unus corresponde a 'ehad en función de artículo indeterminado: Jue 9, 53: et ecce una mulier fragmen molae desuper iaciens; $1 \operatorname{Re} 19,4$ : et sederet subter unam iuniperum; $1 \mathrm{Sm} 27,1$ : aliquando incidam una die in manus Saul; Dan 8, 13: dixit unus sanctus alteri; $\mathrm{Ag} \mathrm{2,} \mathrm{7:} \mathrm{adhuc}$ unum modicum est, et ego commouebo caelum. Además, hay muchos

32 Leumann-Hofmann-Szantyr, o. c., p. 178.

33 Cf. Köhler - W. Baumgartner, o. c., p. 30.

34 Cf. P. Joüon, o. c., p. 428; L. Köhler - W. Baumgartner, o. c., p. 29; U. Rapallo, l. c., p. 413. 
textos en los que unus con sentido de artículo indeterminado va detrás del sustantivo, como, por ejemplo, $1 \mathrm{Sm} \mathrm{1,} \mathrm{1:} \mathrm{fuit} \mathrm{uir} \mathrm{unus;} \mathrm{Dan} \mathrm{10,} \mathrm{5:}$ et ecce uir unus; cf. $1 \mathrm{Sm} 9,12 ; 1 \operatorname{Re} 20,13 ; 2 \operatorname{Re} 8,6 ; 12,9 ; \operatorname{Ez} 8,8$; 37, 16; Dan 8, 3, etc. Para los textos de la Vetus Latina remitimos a Rönsch ${ }^{35}$.

\section{B) Usos Negativos}

Entre los usos con valor negativo de unus hay que señalar las fórmulas bíblicas constituidas por unus en combinación con una partícula negativa (non, neque, ne), que puede preceder o seguir al pronombre. Se trata siempre de una traducción literal de los correspondientes giros hebreos, formados por 'ehad, "uno», en combinación con la negación $l o$ ', "no" o 'al, "no», colocada delante o detrás de la palabra.

En el latín bíblico se presentan tres tipos de fórmulas negativas, uno, constituido por la formación popular neque (o nec) unus ( $\mathrm{y}$ ne unus $)^{36}$, pero que en la Biblia latina es un hebraísmo, al menos en cuanto a la frecuencia de su aparición y al hecho de que siempre corrèsponde al giro hebreo, y otros dos, formados por la negación non delante o detrás de unus, que son giros propios de la Biblia latina y hebraísmos semánticos. Veamos cada uno de ellos en particular:

1) Nec unus = "nadie, ninguno»; ne unus = «nadie, ninguno, $\mathrm{ni}$ uno»: equivalen a nemo, nullus: Ex 14, 28: nec unus quidem superfuit; Jos 11, 15: non praeteriit... nec unum quidem uerbum; cf. Is 40, 26; 1 Mc 7, 46, etc. Ex 8, 31: non superfuit ne una quidem; Jos 8, 17: et ne unus quidem... remansisset; cf. Ex 10, 19; Num 31, 49; Jos 27, 43;

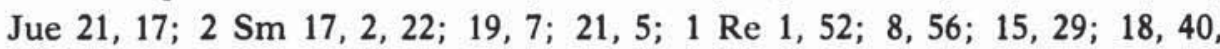
etcétera.

2) Vnus... non $=$ "nadie, ninguno»: equivale a nemo, nullus: Jos 23, 14: de uerbis... unum non praeterierit incassum (= de las palabras... ninguna fallaría); y continúa en el N. T.: Mt 10, 29: unus ex illis non cadet (= ninguno de ellos caerá); otros textos en: Sal 105,11 ; Is 34 , 16; Mt 5, 18; Lc 12, 6, etc.

3) Non... unus $=$ "nadie, ninguno»: equivale a nerno, nullus: $2 \mathrm{Sm}$ 13, 30: non remansit ex eis saltem unus (= no quedó ninguno [o ni

35 H. Rönsch, Itala und Vulgata, Munich $1965_{2}$, p. 425 (reimpr. de 1874).

36 Cf. Leumann-Hofmann-Szantyr, o. c., p. 188. 
siquiera uno] de ellos); Judit 10, 13: ut non cadat uir unus de exercitu (= de modo que no perezca nadie [o ningún hombre] del ejército); Sal 13, 1, 3: non usque ad unum (= ni uno siquiera = ninguno); cf. la misma fórmula en Sal 52, 4. Y otro texto en Judit 5, 13, etc.

\section{$\mathrm{X}$. VNVSOVISQVE}

El pronombre indefinido de distribución unusquisque, "cada uno", tiene a veces en el latín bíblico la acepción de "nadie, ninguno», cuando va unido a la partícula de negación non, que puede preceder o seguir al pronombre. Esta expresión de la Biblia latina es la traducción literal del giro hebreo, formado por el sustantivo 'iš, «hombre, varón", con valor de indefinido, y una partícula negativa, generalmente $l o$, "no" o 'al, "no", que precede o sigue al sustantivo. En estos casos unusquisque... non corresponde a las fórmulas indefinidas ya estudiadas homo... non y uir... non; y non... unusquisque corresponde a non... homo y non... uir, ya que los traductores bíblicos traducen la palabra hebrea 'iš indistintamente por homo, uir o unusquisque. He aquí algunos ejemplos:

1) Vnusquisque... non = «nadie, ningunon: Vnusquisque non iudicet (que nadie juzgue) (Os 4, 4). Vnusquisque abominationes... non proiecit (nadie arrojó sus abominaciones) (Ez 20, 8; cf. Ecclo 16, 28). Vnusquisque fratrem suum non coarctabit (nadie cierra el camino al otro) (Joel 2, 8; cf. Zac 8, 17).

2) Non... unusquisque $=$ "nadie, ninguno»: Vt non dispergatur populus meus unusquisque a possessione sua (para que nadie de mi pueblo [lit. mi pueblo, nadie] sea privado de su propiedad) $(\mathrm{Ez} 46,18) . V t$ non conuerteretur unusquisque a malitia sua (de modo que nadie se convirtiera de su maldad) (Jer 23, 14).

El giro continúa en el N. T.: Non docebit unusquisque proximum suum, et unusquisque fratem suum (nadie enseñará a su prójimo, ni nadie a su vecino, es decir, "no tendrán necesidad de enseñarse unos a otros", ya que las dos fórmulas anteriores son expresiones de reciprocidad). El texto de Jer 31, 34, que cita Hebr 8, 11, dice así en la Vulgata: Non docebit ultra uir proximum suum, et uir fratrem suum, en donde se demuestra la equivalencia entre unusquisque y uir. El texto de Hebr. 8, 11 depende naturalmente de los Setenta, que han traducido

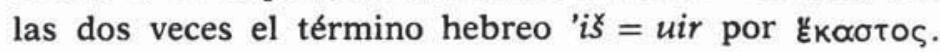




\section{PARTICIPIO PARONOMASTICO}

En hebreo el participio usado paronomásticamente puede represen$\operatorname{tar}$ a veces a un sujeto indeterminado, equivaliendo a un pronombre indefinido, "alguien, alguno», o en frases negativas, "nadie, ninguno» "7. Esta construcción realmente novedosa para la lengua latina ha sido evitada sistemáticamente por los traductores latinos, por eso, es difícil detectarla en su forma pura. Algún caso, sin embargo, puede encontrarse, como los dos siguientes: quod, cum aspexerit uidens... deuorabit illud (que, cuando alguien la ve $[=$ la breva $] ..$ se la come) (Is 28,4 ). Quia nolo mortem morientis (porque no quiero la muerte de nadie) (Ez 18, 32). Ordinariamente Jerónimo en estos casos traduce el participio por una oración de relativo, evitando de este modo la construcción hebrea. Así por ejemplo: Jer 9, 23: sed in hoc glorietur, qui gloriatur (sino que, si alguno se gloría, se gloríe en esto; la traducción literal evitada seria: sed in hoc glorietur glorians); Is 16, 10: non calcabit qui calcare consueuerat (no pisará nadie; la traducción literal evitada sería: non calcabit calcans); Am 9, 1: fugient, et non saluabitur ex eis qui fugerit (huirán y no se salvará ninguno de ellos; la traducción literal evitada sería: fugient, et non saluabitur ex eis fugiens). Otras veces Jerónimo transforma el participio en un indefinido; por ejemplo: Num 6, 9: sin autem mortuus fuerit quispiam; la traducción literal evitada sería: sin autem mortuus fuerit moriens; $2 \mathrm{Sm} \mathrm{17,} \mathrm{9:} \mathrm{audiet} \mathrm{quicumque}$ audierit; la traducción literal evitada sería: audiet audiens; Ez 33, 4: audiens autem quisquis ille est; la traducción literal evitada sería: audiet autem audiens.

En cambio, no pertenecen a este tipo de construcción, aunque por la forma externa sí lo parecen, frases como éstas: Is 6, 9: audite audientes, et nolite intelligere, cuya traducción es: «oíd bien y no entendáis», frase recogida en el N. T. con pequeñas variantes, cf. Mt 13, 14: auditu audietis, et non intelligetis; Act 28, 26: aure audietis, et non intelligetis; o esta otra: Is 55, 2: audite audientes me et comedite bonum, cuyo sentido y traducción es: «oídme bien y comeréis cosas buenas»; o esta otra: Mt 13, 14: et uidentes uidebitis, et non uidebitis, cuyo sentido y traducción es: "veréis bien, pero no veréis (= entenderéis)», conservada también por Act 28,26 con una pequeña variante: et uidentes uidebitis, et non perspicietis, y que son ambas citas literales de Is 6, 9: et uidete uisionem, et nolite cognoscere. $\mathrm{Y}$ decimos que no se trata del

37 Cf. P. Joüon, o. c., p. 473; K. Beyer, o. c., p. 142.

LII, $2 \cdot \bullet-5$ 
mismo tipo de construcción, porque en hebreo en estos últimos casos no se trata de participios usados paronomásticamente, sino de infinitivos absolutos con valor de afirmación, para recalcar la idea o dar la certeza ${ }^{38}$, lo mismo que las conocidas frases de la Vulgata morte morieris (morirás ciertamente) (Gen 2, 17; 3, 4; 20, 7; 26, 11; Ex 19, 12; 21,12 , etc., etc.; congregatione congregabo (reuniré ciertamente) (Miq $2,12)$; plorans plorauit (lloró sin cesar) (Lam 1, 2); contestans contestatus sum patres uestros (bien advertí a vuestros padres) (Jer 11, 7); conterens non conteram domum Iacob (no aplastaré del todo a la casa de Jacob) (Am 9, 8); frases que continúan en el N. T.: uidens uidi afflictionem populi mei (he visto muy bien la aflicción de mi pueblo) (Act 7, 34); benedicens benedicam te, et multiplicans multiplicabo te (te bendeciré muchísimo [ $=$ te colmaré de bendiciones] y te acrecentaré en gran manera) (Hebr 6, 14) ${ }^{39}$. Este tipo de frases, pues, no tienen nada que ver con el participio paronomástico.

\section{FRATER}

El sustantivo frater en cuanto traducción del hebreo 'ah, "hermano» (de sangre, de raza, de pueblo) y del griego $\alpha \delta \varepsilon \lambda \phi \delta ́ \varsigma$, "hermano» (de sangre, de raza, de religión, cualquier hombre), posee en el latín bíblico una gran variedad de acepciones indefinidas; pero se usa sobre todo como suplente de expresiones de reciprocidad. Veamos ahora cada una de estas funciones en particular.

1. Frater en función de pronombre indefinido.

De entre los muchos textos que podrían aducirse, sólo vamos a citar algunos, cuyo sentido indefinido es más evidente.

a) Frater $=$ «cualquiera, quienquiera»:

De manu uiri et fratris eius requiram animam hominis (de la mano de cualquiera (uiri) y de quienquiera (fratris eius) reclamaré la vida del hombre) (Gen 9, 5): Dios pedirá cuentas a todos y a cada uno del derramamiento de la sangre del hombre.

b) Frater $=$ «alguien, uno»:

Sicut latro consurgit contra fratrem suum, et occidit animam eius (como un ladrón se lanza sobre alguien [uno] y lo mata) (Deut 22, 26):

38 Cf. P. Joüion, o. c., p. 349 s.

39 Cf. M. Zerwick, Graecitas biblica, Roma $1955_{3}$, p. 108. 
es evidente que aquí no se trata de un ladrón que mata a «un hermano», sino a «un hombre» cualquiera. El giro continúa en el N. T.: frater es el "prójimo», "uno cualquiera», «todo hombre»: Omnis qui irascitur fratri suo (cualquiera que se encolerice con alguien [otro]) (Mt 5, 22); qui autem dixerit fratri suo, raca (pero el que llame a otro [alguien] «imbécil») (Mt 5, 22). Et ibi recordatus fueris quia frater tuus habet aliquid aduersum te (y allí [en el altar] te acuerdas de que alguien tiene algo contra ti) (Mt 5, 23); uade prius reconciliari fratri tuo (vete primero a reconciliarte con él) (Mt 5, 24). Si peccauerit in te frater tuus (si alguien peca contra ti) (Mt 18, 15; cf. Lc 17, 3). Quoties peccabit in me frater meus, et dimittam ei? (¿cuántas veces tengo que perdonar a uno [alguien] que me ofenda?) (Mt 18, 21). Nolite detrahere alterutrum, fratres. Qui detrahit fratri aut qui iudicat fratrem suum (no habléis mal unos de otros, hermanos. El que habla mal de otro [alguien] o juzga a otro [alguien]) (Sant 4, 11). Qui scit fratrem suum peccare (el que sabe que alguien [uno] comete un pecado) (1 Jn 5, 16). Y otros textos que omitimos.

c) Frater... non / non... frater $=$ «nadie, ninguno»:

Frater non redimit, redimet homo (nadie libera, liberará alguien) (Sal 48, 8): el texto latino evidentemente es confuso, y la confusión viene del propio texto original, que está mal conservado; la traducción correcta sería: "pues nadie se liberará a sí mismo» y en latín bíblico se diria: neque enim homo liberabit seipsum. Ya sabemos que non homo equivale a «nadie». Et domum fratris tui ne ingrediaris (y no entres en la casa de nadie) (Prov 27, 10): el contexto deja entender claramente que no se trata de la casa de "un hermano», sino de «un hombre cualquierax: de nadie. Non oderis fratrem tuum (no odies a nadie) (Lev 19, 17): también aquí el contexto se refiere a «cualquier hombre», aunque limitado a «cualquier hombre israelita». Vnusquisque se a proximo suo custodiat et in omni fratre suo non habeat fiduciam (que cada uno se guarde del otro y no tenga confianza en nadie); quia omnis frater supplantans supplantabit (porque todos ponen zancadillas) et omnis amicus fraudulenter incedet (y todos proceden con engaño). Et uir fratrem suum deridebit (se engañan unos a otros) ( $\operatorname{Jer} 9,3,4)$.

2. Frater en función de pronombre recíproco.

En la lengua hebrea la combinación de 'iš, «hombre, varón», con 'ah, "hermano», es el modo normal de expresar la idea de reciprocidad ${ }^{40}$. Los traductores latinos de la Biblia han conservado el giro hebreo

40 Cf. P. Joüon, o. c., p. 454 s. 
en varias fórmulas de reciprocidad, en las que entra como segundo elemento el sustantivo frater. Las fórmulas son las siguientes ${ }^{41}$ :

a) Vnusquisque fratrem suum, "cada uno a otro": "unos a otros" (Joel 2, 8; Mal 2, 10, y continúa en el N. T., cf. Hebr 8, 11). Esta fórmula admite variantes según los casos en que se encuentre frater: dativo (Is 41, 6; Jer 34, 17; y en el N. T., cf. Mt 18, 35); acusativo con ud (Jer 23, 35; Ez 4, 17; 24, 23); acusativo con in (Ez 38, 21); acusativo con contra (Jer 25, 26); ablativo con $\operatorname{cum}(\mathrm{Zac} 7,9)$.

b) Vir fratrem suum, "uno a otro»: "unos a otros» (Is 3, 6; Jer 9, $5 ; 19,2 ; 13,14 ; 23,35 ; 25,26 ; 31,34 ;$ Miq 7, 2). También esta fórmula admite variantes según los casos en que se encuentra frater, como hemos especificado al hablar de uir.

c) Singuli super fratres suos, "cada uno de ellos sobre los otros" (Lev 26, 37).

d) Alterutrum a fratre suo, (se apartaron) "el uno del otro" (Gen $13,11)$.

e) Nemo fratrem suum, "nadie (veía) a otro»: "no se veían unos a otros» $(\operatorname{Ex~10,23).}$

\section{PROXIMVS / PROXIMA}

El sustantivo proximus en cuanto traducción del hebreo $r e^{*} a$, "compañero, prójimo, amigo, colega, vecino» o del griego $\pi \lambda \eta$ olov, «prójimo, compañero, vecino, camarada", y proxima en cuanto traducción del hebreo re'ah / re'uth, "compañera, amiga, vecina", presentan en el latín bíblico una gran variedad de acepciones indefinidas, y se usan sobre todo como segundo término en la expresión de la reciprocidad ${ }^{42}$. Veamos ahora cada una de estas funciones en concreto.

1. Proximus en función de pronombre indefinido.

En la Biblia el sustantivo proximus significaba primitivamente "compañero, amigo, camarada», es decir, el hombre con el que se tenían unas relaciones concretas. Pero poco a poco fue adquiriendo el sentido más amplio de «los demás, los otros» en general, esto es, adquirió la acepción de un verdadero pronombre indefinido.

41 Cf. O. García de la Fuente, «Expresión de la reciprocidad», l. c., p. 167 ss.

42 P. Joüon, o. c., p. 454 s.; L. Köhler-W. Baumgartner, Lexicon in Veteris Testamenti libros, Leiden 1958 , p. 897 s. $\left(r e^{\circ} a\right)$. 
a) Proximus $=$ «alguien, uno»:

Qui percusserit proximum suum nesciens (el que mate a alguien [o a otro] sin querer) (Deut 19, 4). Ingressus uineam proximi tui (si entras en la viña de alguien [o de otro]) (Deut 23, 24); etc.

b) Proximus $=$ "otro»:

Quizá ésta sea la acepción más frecuente de proximus. Por lo menos, la mayoría de los textos admiten esta interpretación. Y comencemos por la conocida frase "la mujer del prójimo, la mujer de tu prójimo». Esta expresión, que aparece decenas de veces en la Escritura, admite siempre la acepción y la traducción de "prójimo" $=$ "otro" ${ }^{43}$. El propio Jerónimo, que traduce habitualmente uxor proximi o uxor proximi tui, sui (cf. Lev 18, 20; Deut 22, 24; Jer 5, 8; Ez 18, 6, 15; 18, 11; 22, 11; 33, 26; Prov 6, 29, etc.), reconoce esta equivalencia, al traducir de dos maneras la misma expresión hebrea. He aquí un texto: Si moechatus quis fuerit cum uxore alterius, et adulterium perpetrauerit cum uxore proximi sui (Lev 20, 10); la frase puede, pues, traducirse siempre «la mujer de otro", ya que ésta es su verdadera correspondencia.

Pero podemos aducir otros textos, como los siguientes: Noli fieri pro amico inimicus proximo (no te hagas a causa de uno enemigo de otro) (Ecclo 6, 1). Fili mi, si spoponderis pro amico tuo (hijo mío, si te has hecho fiador de alguien [o de otro])... temetipsum libera, quia incidisti in manum proximi tui (líbrate, puesto que has caído en manos de otro) (Prov 6, 1, 3). Dabit illud (= regnum) proximo tuo Dauid (= lo dará [ = el reino] a otro, es decir, a David) (1 Sm 28, 17). Tollam uxores... et dabo proximo tuo (= tomaré a tus mujeres y las daré a otro) (2 $\mathrm{Sm} \mathrm{12,11).} \mathrm{Y} \mathrm{otros} \mathrm{textos} \mathrm{parecidos.}$

\section{Proximus / proxima en función de pronombre recíproco.}

En la lengua hebrea la combinación de 'iš, «hombre, varón», y de 'adam, "hombre», con $r e a$, "compañero, prójimo, amigo, colega, vecino», o con $r e^{`} a h / r e^{`} u t h$, "compañera, amiga, vecina", es un giro normal para expresar la idea de reciprocidad ${ }^{44}$. Los traductores latinos de la Biblia han conservado el modismo hebreo a través de varias fórmulas de reciprocidad, en las que entra siempre como segundo elemento el sustantivo proximus / proxima. Las fórmulas son las siguientes ${ }^{45}$ :

43 Ibid., p. 897.

44 Ibid., p. 900 (re'uth).

45 Cf. O. García de la Fuente, «Expresión de la reciprocidad», l. c., p. 166 ss. 
a) Vnusquisque proximum suum, "cada uno a otro»: "unos a otros» (Lev 19, 11, y continúa en el N. T., cf. Hebr 8, 11). Esta fórmula presenta muchas variantes según los casos en que se encuentra proximus. La traducción es siempre la misma con la variante normal del caso o de la preposición: en dativo (Is 41, 6; Jer 22, 8; Rom 15, 2); en dativo sólo el sibi (Ecclo 16, 28); en acusativo de plural (Num 25, 5); en genitivo (Gen 11, 7; Jer 5, 8; Ez 22, 11; 33, 26; Zac 11, 6; 11, 9); en acusativo con ad (1 Sm 14, 20; Jer 23, 27, 35; 1 Mc 3, 43); en ablativo con $a$ (Jer 23, 30); con de (Ecclo 17, 12); con cum (Zac 8, 16; Mal 3, 16; Ef 4, 25); en acusativo con contra (Zac 8, 10).

b) Vnaquaequae proximam suam, "cada una (enseñe) a la otra»: "enseñad unas a otras» (Jer 9, 20).

c) Vir proximum suum, "uno a otro": "unos a otros" (Jer 31, 34). La fórmula aparece en otros casos, pero siempre con el mismo significado recíproco, como hemos señalado antes al tratar de uir.

d) Homo proximo suo, "uno a otro": "unos a otros" (Rut 4,7 ). También esta fórmula aparece en otros casos, como hemos señalado más arriba, al tratar de homo.

e) Nullus cum proximo suo, "nadie con el otro»: "nadie con los demás» (Judit 15, 2).

f) Singuli ad proximos suos, "los unos a los otros» (Jue 10, 18).

g) Alter ad proximum suum, "el uno al otro»: "los unos a los otros» (Gen 11, 3; Ex 21, 18).

h) Quispiam in proximum suum, «alguien contra otro" $(2$ Cro 6, 22).

i) Singuli a proximo suo non recedent (ninguno de ellos se separa del otro) (Joel 2, 8: V. L.).

j) Aliquis proximo suo, "alguien a otro" (Jue 7,13$)$.

\section{AMICVS}

El sustantivo amicus como traducción del hebreo $r e$ " $a$, "compañero", prójimo, amigo, colega, vecino", presenta en el latín bíblico varios em. pleos indefinidos, además de su uso en fórmulas de reciprocidad. Veamos cada uno de estos usos en particular.

1. Amicus en función de pronombre indefinido.

Las acepciones indefinidas de amicus siguen una línea paralela a las de proximus, ya que ambos términos responden a la misma palabra hebrea $\left(r e^{*} a\right)$, que Jerónimo traduce unas veces por amicus, otras por 
proximus, otras por otros sustantivos, como luego veremos. Incluso hay textos paralelos en los que aparecen simultáneamente amicus y proximus.

a) Amicus = "alguien, uno":

Ferrumque lapsum de manubrio amicum eius percusserit et occiderit (y saliendo el hierro del mango golpea a alguien [o a uno] y lo mata (Deut 19,5). Nótese que el texto comienza diciendo: Qui percusserit proximum suum nesciens (el que mata a alguien sin quererlo); tanto proximus como amicus corresponden a la misma palabra $\left(r e^{\prime} a\right)$ y ambos tienen evidentemente sentido indefinido. Si introieris in segetem amici tui (si entras en la mies de alguien) (Deut 23, 25). El precepto - propiamente la licencia- se refiere naturalmente a "cualquiera", no precisamente a la mies de un "amigo"; lo mismo que vimos antes con respecto a "la entrada en la viña de alguien» (ingressus uineam proximi tui) (Deut 23, 24). En ambos casos no se trata de un "prójimo" o un "amigo" en sentido estricto, sino de "alguien", de una persona "cualquiera". Si spoponderis pro amico tuo (si te has hecho fiador de alguien [o de otro]) (Prov 6, 1; véase antes en la palabra proximus). Noli fieri pro amico inimicus proximo (no te hagas a causa de uno enemigo de otro) (Ecclo 6,1). Est qui prae confusione promittit amico et lucratus est cum inimicum gratis (hay quien por timidez hace promesas a alguien [a uno] y así por nada se gana a un enemigo) (Ecclo 20, 25).

b) Amicus = "otro, los demás»:

Putaui quod odisses eam, et ideo tradidi illam amico tuo (pensé que ya no la querías y por eso se la di a otro) (Jue 15, 2); se trata de la mujer de Sansón, y quien pronuncia la frase anterior es el padre de la mujer; evidentemente no pretende entregar la esposa de Sansón a uno de sus "amigos", sino a "otro" hombre cualquiera. Ferrum ferro exacuitur, et homo exacuit faciem amici sui (el hierro se afina con hierro y un hombre se afina con otro) (Prov 27, 17). Qui despicit amicum suum indigens corde est (quien desprecia a otro es un insensato) (Prov 11, 12). Ita uir qui fraudulenter nocet amico suo, et cum deprehensus fuerit dicit: Ludens feci (tal es el hombre que engaña a otro y al ser descubierto dice: "Lo hice en broma") (Prov 26, 19). Et moechati sunt in uxores amicorum suorum (cometieron adulterio con las mujeres de otros) (Jer 29, 23); obsérvese que la frase habitual en este caso sería proximorum suorum, ya que el traductor latino habla siempre de uxor proximi tui, sui. Dilige mulierem dilectam amico et adulteram (ama a

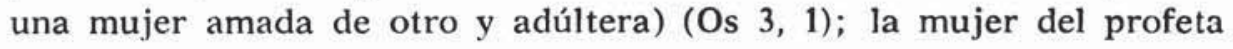


Oseas no se había ido con un "amigo" del profeta, sino con "otro" hombre cualquiera, cuyo nombre no se indica; y Dios le manda que, a pesar de que sea infiel, siga amándola. Vae qui potum dat amico suo mittens fel suum, et inebrians ut aspiciat nuditatem eius ( $j$ ay del que da de beber a otro echando su veneno hasta embriagarlo para ver sus desnudeces!) (Hab 2, 15). Homo qui blandis fictisque sermonibus loquitur amico suo, rete expandit gressibus eius (el hombre que adula a otro pone una red bajo sus pies) (Prov 29, 5). Ante mortem benefac amico tuo (antes de morir haz el bien a los demás) (Ecclo 14, 13).

c) Amicus = "persona indeterminada, fulano":

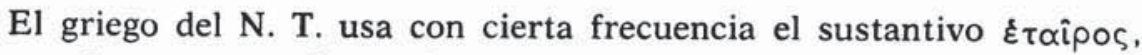
"compañero, camarada, amigo", en vocativo $\varepsilon \tau \propto \hat{\imath} \rho \varepsilon$ para dirigirse o interpelar a una persona cuyo nombre se ignora ${ }^{46}$. Los traductores latinos han vertido esa palabra por amicus / amice: amice, non facio tibi iniuriam (Mt 20, 13); amice, quomodo huc intrasti? (Mt 22, 12); amice, commoda mihi tres panes (Lc 11, 5); amice, ascende superius $(\mathrm{Lc} 14,10)$.

d) Non, nec, ne... amicus = "nadie, ninguno":

$\mathrm{Nec}$ habebit amicum in quo requiescat (ni tendrá a nadie en quien descansar) (Ecclo 28, 20); el texto trata de los peligros de la lengua y en particular de los de la maledicencia (vv. 15-30), por tanto, está más que justificado el sentido general de "nadie» que hemos dado al verso. Nolite credere amico (no creáis en nadie) (Miq 7, 5). También aquí el sentido es general, y no se trata precisamente de poner en guardia contra el "amigo". Ne dicas amico tuo: Vade, et reuertere, cras dabo tibi (no digas a nadie: "Vete y vuelve, mañana te darén) (Prov 3, 28); ne moliaris amico tuo malum, cum ille in te habeat fiduciam (no trames el mal contra nadie, cuando tenga confianza en ti) (Prov 3, 29); ne contendas aduersus hominem frustra, cum ipse tibi nihil mali fecerit (no te querelles contra nadie sin motivo, puesto que no te ha hecho ningún mal) (Prov 3, 30). Los tres versículos se refieren en general a "los demás", no precisamente al "amigo» en sentido estricto. Además, el v. 30 , con la alusión al "hombre» (= nadie) en general, disipa toda duda.

2. Amicus en función de pronombre recíproco.

Como hemos dicho ya a propósito de proximus, en la lengua hebrea la combinación de 'is o de 'adam con re'a constituye el modo normal

46 Cf. F. Zorell, Lexicon Graecum Novi Testamenti, París 1931 ${ }_{2}$, col. 520. 
de expresar la reciprocidad ${ }^{47}$. En la Biblia latina el giro hebreo se conserva en ciertas fórmulas de reciprocidad en las que el segundo elemento es la palabra amicus, traducción literal y normal de re $a$. Estas fórmulas son las siguientes ${ }^{48}$ :

a) Vnusquisque amicum suum, "cada uno al otro": "unos a otros" (Ex 32, 27). La fórmula básica aparece con variantes según los casos; tenemos así el segundo término en dativo: amico suo (Jer 34,17 ); en genitivo (carmen) amici sui (Jer 19, 9); acusativo con ad: ad amicum suum (Jer 34, 15); acusativo con contra: contra amicum suum (Zac 8 , 17). La traducción es siempre la misma: "uno a otro»: "unos a otros».

b) Vir amicum suum, "uno a otro": "unos a otros" (Zac 3, 10). También esta fórmula admite variantes, como ablativo con $a b$ : $a b$ amico suo (Ex 11, 2); acusativo con contra: contra amicum suum (Is 19, 2). El sentido es siempre el mismo: "uno a otro»: "unos a otros".

c) Homo ad amicum suum, "un hombre a otro" (Ex 33, 11).

\section{OTROS TERMINOS MENOS USADOS}

Vamos a agrupar bajo este epígrafe otros varios términos, bastante menos usados que los anteriores, algunos empleados incluso de manera excepcional, que también tienen sentido indefinido o se utilizan en expresiones de reciprocidad. Son los siguientes:

1) Mulier. El sustantivo hebreo 'iššah, "mujer», femenino de 'iš, "hombre, varón", empleado en combinación con 'ậth, "hermana", femenino de 'ah, "hermano", o con $r e^{\prime} a h / r e^{\prime} u t h$, "compañera, amiga, vecina", femenino de $r e^{\prime} a$, "compañero, prójimo, amigo, vecino", tiene a veces el valor de un verdadero pronombre recíproco ${ }^{49}$. Como este uso debería resultar bastante chocante para los hablantes latinos, Jerónimo y la Vetus Latina suelen evitar este modismo, y en su lugar emplean fórmulas de reciprocidad normales, como, por ejemplo, sibi mutuo (Ex $26,3)$, altera ad alteram $(\mathrm{Ez} 3,13)$, altera alteri $(\mathrm{Ex} 26,5)$, altera contra alteram $(\mathrm{Am} \mathrm{4}, 3)$. $\mathrm{O}$ alguna de éstas en género masculino, como milui, alter ad alterum (Is 34, 15: femenino en hebreo); milui, alter alterum (Is 34, 16: femenino en hebreo); animalia, alterius ad alterum (Ez 1, 9,

47 P. Joüon, o. c., p. 454 s.; L. Köhler-W. Baumgartner, Lexicon, o. c., p. 897 $\left(r e^{*} a\right)$.

48 Cf. O. García de la Fuente, "Expresión de la reciprocidad», l. c., p. $170 \mathrm{~s}$.

49 Cf. P. Joüon, o. c., p. 544; L. Köhler-W. Baumgartner, Lexicon, o. c., p. 900 (re'uth). 
23: femenino en hebreo); unusquisque (carnem) proximi sui, "uno (la carne) del otro" (Zac 11, 9: femenino en hebreo).

Sin embargo, Jerónimo no evita del todo el giro hebreo, pues lo conserva al menos en dos casos: ut postulet... mulier a uicina sua, (que una mujer pida a otra) (Ex 11, 2; 3, 22). Y una tercera vez emplea la fórmula, ya mencionada, unaquaequae proximam suam (enseñad, mujeres, unas a otras) (Jer 9, 20).

Por otra parte, la expresión bíblica bastante frecuente, uir siue mulier, con la que empiezan numerosas prescripciones legales o rituales, admite también una interpretación indefinida, equivalente a "cualquiera (hombre o mujer)" que haga tal y tal cosa. Así en los textos siguientes: Lev 13, 29; 13, 38; 20, 27; Num 5, 6; 6, 2; 17, 2, 5; Deut 29, 18 , etc. Y a su vez, la expresión nec uir nec mulier equivale a "nadie

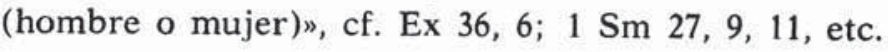

2) Collega. El sustantivo collega en cuanto traducción del hebreo $r e^{`} a$, "compañero, prójimo, amigo, colega", se emplea en el latín bíblico un par de veces en combinación con uir o filius hominis para expresar la idea de reciprocidad. He aquí los textos: Et dixit uir ad collegam suum: Venite et mittamus sortes (se dijeron unos a otros: "Ea, echemos a suertes") (Jon 1, 7). Quomodo iudicatur filius hominis cum collega suo (cómo es juzgada la causa de un hombre con otro) (Job 16, 22).

3) Vicina. El sustantivo uicina en cuanto traducción del hebreo re'uth, "compañera, amiga, vecina", tiene en el latín bíblico un par de veces la acepción de "otra" en expresiones recíprocas, cuando va en combinación con mulier. Así en Ex 11, 2: ut postulet... mulier a uicina sua (que pida una mujer a otra); cf. Ex 3, 22 (aunque en este texto uicina corresponde a otra palabra hebrea distinta de la mencionada).

4) Socius. El sustantivo socius en cuanto traducción del hebreo $r e^{*} a$ y en combinación con uir adquiere el significado de "otro" en expresiones de reciprocidad. Hay un texto claro en la Vulgata: Tunc uir quidam de filiis prophetarum dixit ad socium suum (entonces uno de los hijos de los profetas dijo a otro) (1 Re 20, 35).

5) Dux. Que el sustantivo dux, "jefe», equivalga a un indefinido es una rareza del lenguaje bíblico digna de tenerse en cuenta. $Y$ no cabe duda de que éste es su valor en la frase siguiente: Nolite credere amico, et nolite confidere in duce (= no creáis en nadie, y no confiéis en nadie) (Miq 7, 5). La mención de $d u x$ en el texto que comentamos 
no tiene sentido alguno, puesto que no se trata de confiar o no confiar en los "jefes» de la nación, sino de no confiar en nadie del pueblo. Se trata sencillamente de que Jerónimo no tradujo bien el término 'alūf, que puede significar "persona que manda mil hombres" o "jefe de tribu» y "amigo"; y aquí el significado evidentemente es el de amigo. En este caso hay total paralelismo entre la primera frase: Nolite credere amico y la segunda: Nolite confidere in amico, según la conocida ley de la poesía hebrea, basada en el paralelismo de los miembros de la frase. Ahora bien, amicus es un término que sustituye frecuentemente a los indefinidos, como hemos demostrado más arriba. La frase toma ahora todo su sentido: "no creáis en nadie ni confiéis en nadie"; ni el hijo en el padre ni el padre en el hijo; ni la hija en la madre ni la madre en la hija; ni la nuera en la suegra ni la suegra en la nuera, porque inimici hominis domestici eius, "los enemigos de cada uno (hominis) son las gentes de su propia casa" (Miq 7, 5, 6).

Jerónimo cometió este mismo error otras veces: en Jer 3, 4 traduce: pater meus, dux uirginitatis meae tu es; en vez de dux basta poner amicus para que el sentido sea correcto; en el Sal 55, 14 traduce: $d u x$ meus et notus meus; el sentido es amicus meus.

Después del análisis de los textos, se impone recoger en síntesis las conclusiones más importantes de lo expuesto.

1. El latín bíblico amplía considerablemente las formas de expresar los indefinidos.

a) Frente a los indefinidos propiamentedichos, positivos, de la época clásica: quis, aliquis, quispiam, quisquam, ullus, el latín bíblico emplea además los siguientes sustitutivos: homo, quis hominum; uir, quis uirorum; anima, anima una; frater; proximus; amicus y el participio paronomástico. Y para el concepto de «algo» (aliquid, etc.), además de los citados indefinidos en género neutro, emplea como sustitutivos: uerbum, omne uerbum; sermo; omne. Para el concepto de "uno", "cierto", además de quidam de la época clásica, el latín bíblico utiliza los siguientes sustitutivos: Homo, homo quidam / quidam homo; uir, uir quidam / quidam uir, unus uir quidam; mulier; unus.

b) Frente a los indefinidos propiamente dichos, negativos, de la época clásica: nemo, nullus, el latín bíblico emplea además los siguientes sustitutivos: homo... non / non ... homo; non... homo quisquam; non... filius hominis; omnis homo... non; uir... non / non... 
uir; omnis anima... non / non... omnis anima; omnis... non / non... omnis; uniuersus... non / non... uniuersus; cunctus... non / non... cunctus; unus... non / non... unus; unusquisque... non / non... unusquisque; frater... non / non... frater; non... amicus; non... dux, y el participio paronomástico negativo. Además, frente a nihil de la época clásica, el latín bíblico emplea también los siguientes sustitutivos: non uerbum, non omne uerbum, non ad ullum uerbum; non sermo; omne... non / non... omne.

c) Con respecto a los indefinidos de generalización, frente a quisquis, quicumque, quiuis, quilibet de la época clásica, el latín bíblico utiliza además los siguientes sustitutivos: homo qui, homo homo qui; homo homo quicumque; omnis homo qui, omnis homo quicumque; homo quicumque; homo quilibet; homo quisquam; uir quispiam; anima quae; omnis anima quae; quaecumque anima; omnis anima quaecumque; omnis; frater; unus.

d) Con relación a los indefinidos de distribución, frente a quisque y unusquisque de la época clásica, el latín bíblico emplea también homo, uir y unus.

e) Por lo que respecta a los indefinidos pronominales, frente a alius y alter de la época clásica, el latín bíblico emplea con el mismo valor, sobre todo en fórmulas de reciprocidad, uir, frater, proximus, amicus, collega, uicina, socius y unus.

f) Las fórmulas básicas de reciprocidad, que corresponden siempre a "uno a otro": "unos a otros» son las siguientes: homo proximum suum: uir proximum suum; homo amicum suum: uir amicum suum; homo ad amicum suum; uir fratrem suum; uir ad collegam suum; uir ad socium suum; uir ad uirum; uir et uir; unusquisque fratrem suum. unusquisque proximum suum: unusquisque amicum suum; unaquaequae proximam suam; singuli fratres suos: singuli proximos suos; nemo fratrem suum: nullus proximum suum; alterutrum a fratre suo; alter ad proximum suum; quispiam in proximum suum; aliquis proximo suo; mulier a uicina sua; una uni, unum contra unum, unus et unus.

2. De la exposición anterior se ponen de manifiesto una serie de equivalencias, no sólo por el significado - cosa que ya hemos señalado-, sino por la forma externa; así, por ejemplo, homo qui = anima quae; omnis homo qui =omnis anima quae; omnis homo quicumque = omnis anima quaecumque; homo quicumque = anima quaecumque; homo quidam: quidam homo = uir quidam: quidam uir; quis hominum $=$ quis uirorum; homo... non $=$ uir... non; non... homo $=$ non... uir; omnis homo... non $=$ omnis anima... non; non... uerbum $=$ non... 
sermo, y lo mismo las combinaciones con omnis, uniuersus, cunctus, unus acompañados de la negación, y las varias fórmulas paralelas de reciprocidad.

3. La variedad verdaderamente sorprendente de fórmulas de reciprocidad depende de que los traductores latinos de la Biblia han traducido de distintas maneras las dos palabras hebreas que sirven de base a las fórmulas: así 'iš o 'adam se convierten en homo, uir, unusquisque, singuli, nemo, alterutrum, alter, quispiam, aliquis. Por su parte, $r e^{*} a$ da lugar a los siguientes términos latinos: proximus, amicus, collega, socius. Así las dos típicas fórmulas hebreas de reciprocidad: 'iš... 'ạ e 'iš... re' $a$ han dado origen a más de 20 fórmulas de reciprocidad en el latín bíblico.

4. En la exposición anterior habrá llamado la atención sobre todo el uso amplísimo de homo en el latín bíblico con las más variadas acepciones indefinidas y recíprocas, tales como "uno»; "cierto»; «alguien, alguno»; "cualquiera, quienquiera"; "cada uno»; "nadie, ninguno"; "otro", etc., además de su significado ordinario de "hombre" en sentido real o figurado, colectivo o individual. Con respecto al origen de este empleo indefinido de homo hay que hacer algunas observaciones:

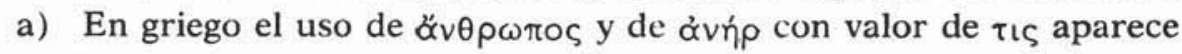
ya en Homero y en el griego clásico ${ }^{50}$; por tanto, su presencia en los Setenta no representa novedad especial. No obstante, dado que esta

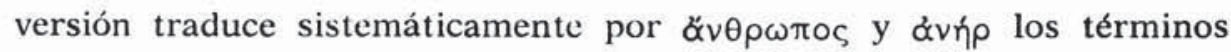
hebreos 'iš o 'adam cuando tienen valor de indefinidos, es lógico admitir un calco semántico hebreo en los Setenta, al menos en base a la frecuencia de este fenómeno en esa versión ${ }^{51}$.

b) En el uso como indefinidos de esos dos términos en el griego del Nuevo Testamento han influido sin duda los Setenta, además del texto original hebreo o arameo.

c) La situación con respecto al uso indefinido de homo y uir en las versiones latinas de la Biblia es distinta de la de la versión griega, ya que en latín no hay testimonios anteriores a las versiones bíblicas. Se trata, pues, de un semitismo, aunque para la Vetus Latina la fuente inmediata ha sido la versión griega. En la Vulgata es un semitismo directo, aunque también se pueda admitir el influjo de los Setenta. El modelo sintáctico bíblico homo dicit, "alguien dice», "uno dice», "se

so R. Kühncr - B. Gerth, Ausführliche Grammatik der griechischen Sprache, I, Hannover $1904_{3}$, p. 272.

51 Cf. U. Rapallo, l. c., p. 389. 
dice», desemboca en la expresión francesa on dit y en la alemana man sagt. En el español medieval era normal el uso de «hombre" por "uno". Bastará citar unos cuantos ejemplos. En el Libro de Alexandre encontramos frases como éstas: "Que quando omne pierde pariente o aver» (2388b); "quando omne se cuida más seguro estar" (2394c); etc., etc. $\mathrm{Y}$ en la versión bíblica medieval romanceada (E6) son totalmente normales traducciones como éstas: "cuemo si echare ombre la semient en tierra" (Mc 4, 26); "¿qué camio dará ombre por su alma?" (Mc 8, 37);

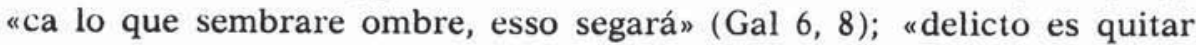
se ombre del bien; o delicto es lo que faz ombre por non saber (Gal 6, 1: comentario entre líneas).

5. El origen del significado de anima como pronombre indefinido en la Biblia latina hay que buscarlo también en el hebreo nefeš. Pero los pasos de esta evolución semántica arrancan del empleo gradual de anima con el significado de "persona, hombre, individuo", y esta acepción no es del todo extraña a las estructuras, tanto del griego como del latín, pues en latín anima se usa a veces con el significado de "persona», por ejemplo, en Hor., Sat. I 5, 41: Plotius et Varius Vergiliusque / ... animae qualis neque candidiores / terra tulit, y Tac., Hist. IV 32: Vos

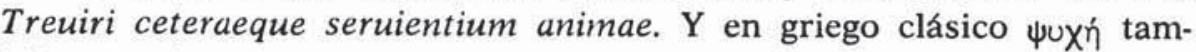
bién significa a veces "hombre, persona» (Pl., Alc. 1, 130c; Esq., Ag. 1457; Arist., Thes. 864). Pero el cambio de anima a pronombre indefinido se verificó por primera vez en el latín bíblico y en el griego de los Setenta ${ }^{52}$.

6. El modelo sintáctico homo homo del latín bíblico, conservado

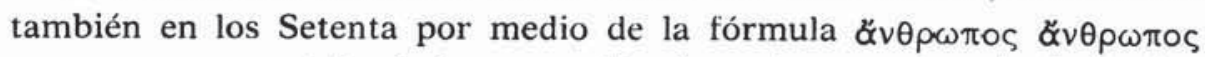
-y a veces por ớvńp đóvńp- es evidentemente un calco sintáctico hebreo. La expresión hebrea 'iš 'iš, de la que se derivan la griega y la latina, tiene sentido distributivo, "cada", "cada uno" - quisque, unusquisque-, como puede verse por otros giros más claros de tipo adverbial, como babboqer babboqer, "mañana por mañana", "cada mañana", "todas las mañanas" - de be, "en, por», y boqer, "mañana»-, conservados igualmente por las versiones latinas, por ejemplo: Lev 6, 12, mane mane ( $V . L$. ): mane per singulos dies $(\mathrm{Vg}$.); Is 50,4 ; Sof 3, 5: mane mane; Ez 46, 14, 15: cata mane mane, y en yôm beyôm, "de día en día": de die in diem (Sal 61,9) —de be, "en, por» y yôm, «día»_" Pero la expresión que comentamos, 'iš 'iš, seguida de la partícula 'ašer,

52 O. García de la Fuente, «Anima», l. c., p. $14 \mathrm{~s}$.

53 P. Joüon, o. c., p. 414. 
"que», da origen al indefinido de generalización "cualquiera que, quienquiera que» - quis, quicumque-, que es la acepción que tienen la expresión latina homo homo qui; homo homo quicumque.

7. Con respecto a la novedad que representa en latín el giro sintáctico non... omnis / omnis... non (lo que es lo mismo que non... uniuersus / uniuersus... non; non... cunctus / cunctus... non) por nihil, nemo, nullus, y que ofrece un esquema idéntico a non... homo / homo... non; non... uir / uir... non, y los demás casos citados antes, hay que hacer algunas observaciones:

a) Estas fórmulas son a veces ambiguas, tanto en hebreo como en latín, porque non... omnis, etc., puede significar "no todo» o "nada». En el primer caso, no existe novedad alguna, ni en latín clásico ni bíblico. Así, Hor., Carm. III 30: Non omnis moriar, significa "no moriré todo" (del todo, totalmente), y Gen 3, 1: ut non comederetis de omni ligno paradisi, no significa que Adán y Eva «no puedan comer de ningún árbol del paraíso", sino que "no pueden comer de todos los árboles del paraíso", ya que Dios sólo les prohibió comer de uno (Gen 3, 2-3) ${ }^{54}$.

b) En griego el esquema fraseológico $\pi \alpha \hat{s}$.... oủ no es desconocido del griego profano; en cambio, no sucede lo mismo con el modelo

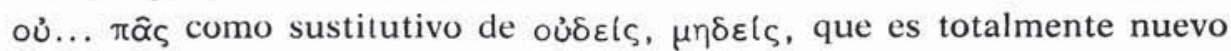
en griego ${ }^{55}$.

c) En latín ambos tipos fraseológicos son nuevos, al menos como sustitutivos de nihil, nemo, nullus; aunque el modelo omnis... non cabe mejor en las estructuras latinas; así en Quint., X 7, 24, omnino non dicere significa "negar absolutamente".

d) En cualquier caso, tanto en griego como en latín, las expresiones omnis... non / non... omnis - y las demás citadas antes- como sustituciones de nihil, nemo, nullus son siempre traducciones literales del hebreo, y por tanto están influidas por la sintaxis semítica.

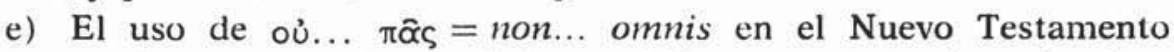
(cf. Lc. 1, 37: non erit impossibile apud Deum omne uerbum (no hay nada imposible para Dios) probablemente depende de los Setenta (cf. Gen 18, 14); pero se trata en último análisis de un semitismo.

f) Relacionado con el esquema fraseológico non... omnis, "nada, nadie, ninguno", existe en hebreo otro giro que ha pasado igualmente a las versiones latinas de la Biblia. Se trata de la frase "no ordenar! no mandar" como equivalente de "prohibir", ya que en hebreo no existe

54 O. García de la Fuente, «Uso de non omnis», l. c., p. 264 s.

55 Cf. U. Rapallo, l. c., p. 400. 
el verbo "prohibir" ${ }^{56}$. Los ejemplos que pueden aducirse son muy numerosos. Bastará citar unos cuantos: nisi quod ex ligno de quo praeceperam tibi ne comederes (del cual te prohibí comer), comedisti (Gen 3,11 ; cf. $3,3,17$ ); quae praecepit ut non fierent (las cosas que prohibió que se hicieran) (Lev. 4, 2); quod eis praeceptum non erat (que les habia prohibido) (Lev 10,1); quae ego non praecepi illi, ut diceret (las cosas que yo le prohibí decir) (Deut 18, 20). El giro continúa en el Nuevo Testamento: praecipiendo praecipimus uobis ne doceretis in nomine isto (con toda severidad os hemos prohibido enseñar en este nombre) (Act 5, 28; cf. Mc 6, 8; 7, 36; 9, 8; Mt 12, 16; Lc 8, 56; Act 23, 22; Apoc 9, 4, etc.). Y lo mismo con el verbo mandare: locuti sunt uerbum... quod non mandaui eis (dijeron una cosa... que yo les prohibí) (Jer 29, 23); cf. Jer 32, 35, etc.

Olegario Garcfa de la Fuente

56 P. Joüon, o. c., p. 492. 